\title{
AROUSAL OF EMPATHY AND SUBSEQUENT \\ GENEROSITY IN YOUNG CHILDREN
}

by

JEFFREY A. HOWARD

B.A., Va1paraiso University, 1976

\section{A MASTER'S THESIS}

submitted in partial fulfillment of the

requirements for the degree

MASTER OF SCIENCE

Department of Psychology

\author{
KANSAS STATE UNIVERSITY \\ Manhattan, Kansas
}

1979

Approved by:

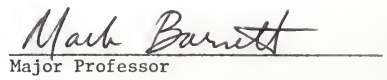


Spec. GII.

List of Tables . 2

Figure

Introduction

Two Views of Empathy . . . . . . . . . . . . 1

Empathy as a Motivational Construct in Altruism . . . . 4

Empathy and Helping Among Adults .......... 8

Theories of the Development and Expression of Empathy . . 9

Developmental Differences in Empathy . . . . . . . 16

Sex Differences in Empathy . . . . . . . . . . 18

Research on Empathy and Altruism: Cognitive Perspectives . 19

Research on Empathy and Altruism: Affective Perspectives . 22

A Critique of the Research on Empathy and Altruism

in Children .................... 25

Present Research . . . . . . . . . . . . . . 27

Method . . . . . . . . . . . . . . . 32

Results ................... . . 40

Discussion .................... . . 51

Footnotes ................. 56

References . . . . . . . . . . . . . . 59

Appendices . . . . . . . . . . . . . . . 68 
Acknowled gments

I would like to express my sincere appreciation to Mark A. Barnett, my major professor, for his guidance and advice throughout the course of this research. His comments and suggestions were very helpful in the preparation of this thesis. I would also like to thank the members of my committee, E. Jerry Phares, Leon Rappoport, and Karen A. Matthews for their efforts in this project. Appreciation is also expressed to' R. Michael Rubison, of the Department of Statistics at Kansas State University, for his advice regarding the tests of significance employed in the present study. And finally, thanks are expressed to my assistant cole Werner for the long hours of pretesting he conducted. 


\section{LIST OF TABLES}

TABLE

PAGE

1. Empathy score descriptive statistics for sex and age level....................... 34

2. Mean number of prize chips donated and number of subjects above and below the median.... . . . . 42

2a. Mean number of prize chips donated and the number of subjects above and below the median for the tests for main effects ............. 43

3. Wilson analysis of the donation data . . . . . . . 44

4. Mean responses to Questions 2 and 3 by condition . . . 47

5. Analysis of responses to Question 2.......... 48

6. Analysis of responses to Question 3.......... 49 
FIGURE

PAGE

1. Distribution of donations for the entire sample . . . 41 


\section{Introduction}

The desire to describe and understand the expression of empathy and its importance in interpersonal relationships is nothing new to those who ponder over the human condition. Stewart (1956) traced the concept of empathy from Plato, who, in his seventh letter, wrote that the kinship of insight or empathy is the highest form of knowledge, being at once the ground and goal of the Ideas. Philosopher Max Scheler $(1928 / 1970)$ argued that the emotional experience of "fellow-feeling" is a necessary component for truly personal relationships.

More contemporary investigators have also focused upon empathy, but particularly upon the importance of empathy in the development and expression of prosocial behaviors. Not unlike many other areas of research, each investigator appears to have his or her own definition of the basic concept; as might be expected, different definitions often lead to different methodologies which, in turn, lead to different results.

Two views of empathy

Hoffman (1975a, 1976, 1977a, 1977b) points out that there are two broad conceptions of empathy, and it will be useful to follow his classification system to understand the perspectives of the researchers to be discussed later in this paper. The first approach conceives of empathy as an awareness or knowledge of the feelings of another person. This is a purely cognitive process of understanding what the other person is feeling. 
The second conception of empathy emphasizes the vicarious affective response a person may experience when exposed to another person's feelings. Hoffman notes that this second definition is closer to what is commonly meant by the word empathy and has been the conception held by most social philosophers throughout a long history of thought and speculation. It seems important to note that, while this is an emotional experience, a cognitive process of ling the emotion must surely be employed. The affective view of empathy, then, is assumed to include both cognitive and affective components.

The difference between the cognitive and affective views is amplified by Feshbach and Roe (1968) who state that, "Empathy as a vicarious affective response may be contingent upon the comprehension of a social event, while social understanding may be independent of an affective response" (p. 133). The cognitive approach emphasizes the accurate recognition of the emotions of another. It is the observer's interpretation of the other's affective state without a similar affective state necessarily being aroused in the observer. As such, it probably would have little theoretical value for the empathy-altruism relationship except as a cue for an observer that an altruistic act may be appropriate (Feshbach, 1978a). Thus, cognitive empathy gives the actor the information necessary for determining that an altruistic act is required, based upon the perception of another's distress. Emotional empathy is believed to be more relevant for altruism research, however, because it provides a potential motivation for action. The empathic arousal felt by an individual could theoretically impell that person to go to the victim's aid. As we sha11 see, the literature on altruism is in need of some such motivational construct. 


\section{Definitions of altruism}

Like empathy, no universally accepted definition of prosocial behavior, or altruism, can be found. Altruism is frequently the label given to such actions as helping or sharing which benefit another at some cost to the actor, with the stipulation that the acts are performed without motivation for personal gain by the actor. Unfortunately, to demonstrate "true" altruism the researcher would be required to show that the actor was not motivated by any desire which could, if fulfilled, lead to a reward or gratification for the actor. This, of course, places an impossible task upon the shoulders of the social scientist because it necessitates a proof of the null hypothesis (Bryan, 1975; Krebs, 1970).

Other definitions of altruism have attempted to circumvent this problem by rephrasing to avoid motivational issues. Another definition, coined by Macaulay and Berkowitz (1970), conceives of altruism as "behavior carried out to benefit another without anticipation of rewards from external sources" (p. 3). This definition does not avoid the null hypothesis problem since the person might be motivated to help someone purely to gain a sense of satisfaction from having helped, but the definition explicitly rules out the anticipation of external rewards as a motivation. Bryan and London (1970) further qualify the description of altruistic behaviors by stating that such behaviors are "intended to benefit the other but which appear to have a high cost to the actor with little possibility of material or social rewards" (p. 200).

The forementioned definitions are still cumbersome and thus most researchers employ narrower operational definitions which allow them 
to ignore the intention problem, and assume that behavior which seems intuitively altruistic is in fact altruism (Rushton, 1976). This poses a serious problem to those interested in finding the sources of prosocial behavior since generally it is the intention behind the action which determines the moral worth of that action. It would appear vital that a motivational component, however difficult to deal with experimentally, be incorporated in any comprehensive view of prosocial behavior.

Empathy as a motivational construct in altruism

The conception of empathy as a vicarious affective response to another's feelings and needs may serve to provide a motivational explanation for prosocial behavior. If an individual's distress arouses a similar feeling in an empathic observer, that observer may be motivated to help to a greater extent than would another person lacking a capacity for empathy. The empathy-helping scenerio might unfold in the following manner: (a) the person in need of help emits cues as to his or her affective state, (b) the empathic individual senses the other's distress, (c) this elicits a similar affect in the observer, and (d) the empathic arousal is translated into appropriate action.

This little episode includes at least three implicit assumptions. First, there is the assumption that affect can influence and/or motivate prosocial behavior. This appears to be a plausible assumption since the influence of affect on altruism is fairly well established (e.g., Harris \& Siebe1, 1975; Isen, 1970; Moore, Underwood, \& Rosenhan, 1973; Rosenhan, Underwood, \& Moore, 1974; Staub, 1974). The majority of the studies cited indicate that negative affect will 
suppress altruism; since the empathic distress aroused by observing someone in distress is presumably experienced as negative affect, this pattern of findings appears problematic. Negative affect has been induced in subjects primarily by having the subjects either discuss and dwell upon negative personal experiences or by giving the subjects a failure experience. These techniques would tend to make one feel sad about oneself. However, there is additional evidence that there may be particular types of negative affect, such as guilt or empathy, which are qualitatively different from simply feeling unhappy about oneself and which may serve to increase helping (Hoffman, 1975a; Staub, 1974). In a recent study (Barnett, King, \& Howard, 1979), second- to fourth-grade children were asked to recall and dwell upon either sad personal experiences or the sad experiences of another individual. The children were subsequently given an opportunity to share their experimental earnings with needy children. It was found that those children who felt badly about another's misfortune, which presumably elicited empathic arousal, shared significantly more prizes than did children who felt sad about personal misfortunes. Therefore, empathy for another's plight is expected to enhance the expression of prosocial behaviors since the attention of the empathic observer is directed to vicariously shared feelings rather than solely upon the individual's own feelings.

The second implicit assumption is that the person will want to relieve the other's distress. Research with adults indicates that the intensity of the affect and the speed of the overt response increase as the number and intensity of the distress cues from the victim increase (Geer \& Jarmecky, 1973; Weiss, Boyer, Lombardo, \& Stich, 
1973). This is not to deny that there may be other factors which will prevent the person from actually helping even if there is a high affective arousal. In many cases, the personal cost may be too great in terms of fear or danger of a physical or social risk involved in the act of helping (Staub, 1974). There may be. an inhibiting "diffusion of responsibility" factor when a person is a member of a crowd of bystanders (Latané \& Darley, 1970). The person may doubt his or her ability to provide the necessary aid to the victim (Lenrow, 1965). Finally, there may be other overriding egoistic concerns such as those which may result from competition (Barnett \& Bryan, 1974). However, given a situation relatively devoid of these conflicting motives and factors, attempts to help are expected to be enhanced under conditions of empathic arousal.

The third assumption is that the cognitive ability and past experience of the individual will serve to translate the emotional arousal into appropriate action. By and large, adults translate their emotions into action without extreme difficulty. Young children, however, may not have a behavioral repertoire sophisticated enough to act appropriately in the face of an empathic arousal to another's distress. For example, they may simply cry in response to another child's cry for help (Hoffman, 1975a).

Conceiving of empathy as a possible motivating force for altruism may offer an important compromise to the earlier "egoistic" critique of the altruism research: by aiding the other, one would reduce one's own empathic distress while simultaneously reducing the distress of the other. However, Hoffman (1977a) argues that an act of giving aid may occasionally be attempted when such effort actually increases the 
empathic distress of the actor. For example, nurses working with terminally ill patients could reduce their own empathic distress by leaving the room but instead they stay to aid the patient. While the "pure versus egoistic altruism" argument can rage on and on depending upon one's theoretical approach to such issues, it is perhaps most fruitful to regard empathy as something having the potential to spur people into prosocial action which benefits another, and accept that the private intentions of the individual may never be unambiguously determined.

A theoretical blending of the notions of empathy and altruism is seen in the writing of Justin Aronfreed (1968, 1970) who states that:

A concept of altruism must focus on a component of behavioral control that is directed to effects which will be produced in the experience of another person. Regardless of whether such effects are directly observable or are given a cognitive representation by the actor, the altruistic component of their affective value must be transmitted by the actor's empathic or vicarious experience. Empathic or vicarious control is the criterion of the truely altruistic act. (1970, p. 105)

Thus Aronfreed defines altruism in terms of the presence or absence of an empathic or vicarious affective experience on the part of the actor. While this definition of altruism has been criticized as being unnecessarily narrow (Macaulay \& Berkowitz, 1970), it points the way toward a theory of altruism which assumes that the actor responds emotionally to the perceived need of another and is motivated by that experience of empathy. 
To summarize, then, empathy can be considered as either cognitive, affective, or both. While both components are undoubtably important, the vicarious experiencing of another individual's affect seems to be the more crucial aspect for altruism research by virtue of its potential motivating power.

Empathy and helping among adults

The research with adults, utilizing a variety of different assessment techniques, has shown a fairly consistent positive relationship between the experience of empathy and prosocial behavior. In a study wherein college students observed a performer in distress, Krebs (1975) found that "when required to make a choice between helping themselves at a cost to the performer or helping the performer at a cost to themselves, the subjects who reacted most empathically behaved most altruistica11y" (p. 1134). Aderman and Berkowitz (1970) manipulated the empathy of college students by instructing them to imagine how they would feel in the place of an unfortunate student whose plight was discussed via a tape recording. Those students who empathized the most, as measured by a mood questionnaire, also showed the greatest helping. Mehrabian and Epstein (1972) found that highly empathic college students gave significantly less shock to a close proximity "learner" in a Buss (1961) aggression paradigm; they also found a positive relationship between empathy and helping among female college students in a second study. In a jury simulation study, highly empathic college students who heard a plea by the defense attorney designed to elicit empathizing with his client judged the defendant to be more innocent than did those who did not hear the plea which encouraged empathizing (Archer, Foushee, \& Davis, 1977, Experiment 2). 
In addition, there was a marginally significant $(p<.06)$ tendency for highly empathic subjects receiving the empathic appeal to report a greater attempt to place themselves "in the defendant's position" than less empathic subjects.

Coke, Batson, and McDavis (1978) attempted to achieve an understanding of the relationships among role-taking skills, empathy, and altruism. In a series of studies with college students, they determined that taking the perspective of another individual facilitates empathic arousal which, in turn, increases helping. After a lengthy review of investigations of empathy and helping with adult samples, Batson, Darley, and Coke (1978) concluded that there is ample empirical support for the theoretical assertion that empathic arousal is an important mediator of helping.

Although empathy has been found to play an important motivational role in the adult's prosocial behavior, empathy may play a changing role in prosocial behavior as the child matures. Since it is presumably during childhood that the link between empathy and altruism is established, the development and expression of empathy in children has attracted the attention of several theorists. It is to the writings of these theorists that we now turn. Theories of the development and expression of empathy

While the research on empathy has tended to emphasize either cognitive or affective conceptions of empathy, an adequate developmental approach must include both components. Norma Feshbach and Martin Hoffman have each attempted this synthesis. After considering their respective theoretical approaches, research on developmental and sex differences in empathy and helping will be explored. 
Feshbach (1975) defines empathy as an emotional match between the feelings of the observed and the observer. She proposes a three component model of empathy which attempts to account for both the cognitive and the affective contributions. The first two components are cognitive: (a) the child must have the ability to discriminate the perspective of the other person from their own, and (b) a more advanced skill, the child must be able to discriminate the "role" of the other from his or her own. The third requirement is that the child must have a capacity for, and responsiveness to, emotion. Each of these probably change as the child grows, matures, and accumulates additional experiences relevant to the feelings of others. According to Feshbach, all three are necessary for empathy.

Her ideas are operationalized in an empathy measure she devised for use with young children. The Feshbach and Roe (1968) measure consists of eight sets of slides, each with a short narrative. The slides present situations in which a child is angry, happy, sad, or afraid. After viewing each set of slides and listening to the story which accompanies it, the child is asked by the experimenter "How do you feel?", or "Tell me how you feel." The child's responses are scored for accuracy in matching the affect of the target character. In this way, the experimenter obtains a measure of the child's ability to feel what the child in the slides is probably feeling. It is readily apparent that the emphasis is upon the child's affective response. This emphasis reflects Feshbach's belief that it is the emotional response which is most important in empathy. She states:

While empathy presupposes some degree of social understanding, the converse is not true. Understanding the 
feelings of another person does not necessarily lead to an empathic response. Consequent1y, while the cognitive dimension of empathy is important, it is the affective component that gives the empathy construct its unique property. (1975, p. 26)

Feshbach sees empathy as relating positively to a cluster of prosocial behaviors and constructs such as moral judgment, and negatively to antisocial behaviors and constructs such as aggression. In this broad conceptualization we find Feshbach's view that perceiving and experiencing another's affect should enhance prosocial behaviors and inhibit antisocial behaviors. For example, an empathic individual should be less aggressive because cognitively he or she understands the other's perspective in a potential conflict situation, and emotionally he or she can anticipate feeling the pain of the other.

Following this 1ine of reasoning, Feshbach and Feshbach (1969) compared teacher's ratings of children's aggressiveness with each child's performance on the Feshbach and Roe empathy measure. In boys ages six and seven, the relationship was in the predicted direction with highly empathic boys being less aggressive. This finding was later replicated by Huckaby (1971). In another recent study using the Feshbach and Roe (1968) empathy measure, highly competitive boys were found to be significantly less empathic than less competitive boys (Barnett, Matthews, \& Howard, 1979). This provides additional support for Feshbach's contention that empathy is negatively related to selfish, antisocial behaviors since competitiveness can be considered conceptually similar to aggressiveness. 
To summarize, Feshbach's view of empathy is based upon an affective match of observer and observed, with the emphasis on the emotional component. Her primary measure of empathy is the selfreported affective response to a slide/story sequence. The motivational aspect of empathy is derived from logical and empirical support for the contention that empathy is associated positively with prosocial constructs and behaviors, and negatively with antisocial behaviors.

Hoffman (1977a) defines empathy as "a largely involuntary vicarious response to affective cues from another person or from his situation" (p. 1). His model is an attempt to explain how affective, cognitive, and motivational factors each play changing and interactive roles in the child's empathy. Unlike most other theorists, Hoffman takes a predominately developmental approach. By incorporating knowledge from other branches of child development, he builds a persuasive argument to support a rather simple contention: empathy leads to altruism.

Hoffman identifies five modes of empathic affect arousal. Although the five modes are arranged in order from simple to complex, they are not intended to form a strict developmental or stage sequence. The first two modes operate in early infancy before the child is able to cognitively distinguish him/herself from the world. The remaining three supersede the first two and continue to function throughout life and may operate simultaneously in any given situation. The modes are not given names, only descriptions. The following is a close paraphrasing of Hoffman's (1977a) explanation of his theoretical model. 
The first mode of empathic affect arousal is found in newborns who will frequently cry in response to the sound of another infant's cry. There is evidence that this early cry is not merely a reflexive response to the annoying stimulus of the noise since the infants do not cry as much to nonhuman noise or computer simulated infant cries which are equa11y loud (Sagi \& Hoffman, 1976; Simner, 1971). While this responsive cry is quite natural and intense and cannot be considered simply an imitative vocal response, it is not a mature empathic response since it lacks a cognitive component. Thus it is mentioned by Hoffman only as a possible precursor of empathic arousal. The second mode appears somewhat later as the infant develops a greater perceptual discrimination capability. It emphasizes the classical conditioning of affect similar to that discussed by Aronfreed and Paska1 (in Aronfreed, 1968), whose research is described more fully on page 22 . Empathy results from the feelings communicated during the physical handling of the infant by the caretaker. In this manner, the infant receives information about the affective state of the caretaker, and responds in kind. If the mother is tense, she may handle the child more rigidly than at other times. Her facial and verbal expressions then become associated with the handling and are conditioned to the affective state which has been passed on to the infant. Of course, stimulus generalization to other individuals is anticipated and the child will eventually show a simple empathic response to the distress of others, albeit without any cognitive understanding of the other's situation.

The third mode is a more advanced version of the classical conditioning of the earlier mode. Instead of the physical mediation 
of the caretaker, cues from another or another's situation can evoke memories and associations with the observer's own past experiences resulting in an empathic affective reaction. Although this mode was intended by Hoffman to show how distress can be vicariously aroused, this mechanism can function for both positive and negative emotional experiences. Not only past distress and unpleasant feelings, but also the pleasant experience of a birthday party, could be elicited in this manner.

The fourth mode of empathic arousal is based upon Lipps' (1906) idea that the physical expression of emotion by one person is an adequate stimulus to elicit that emotion in the observer through an innate process of "motor mimicry." The inner proprioceptive cues of the motor feedback would contribute to the individual's understanding and experiencing of the other's emotional state. Although historically Lipps' theory has largely been ignored, Hoffman cites several studies (see Hoffman, 1977a, for complete references cited) showing empirical support, and so includes it as a possible source or mechanism of affective arousal.

The fifth and final mode of empathic affective arousal is based upon the experimental technique of Stotland (1969) who asked college students to imagine how they would feel if they themselves were in the target character's situation, experiencing all of the same stimuli. In that experiment, subjects instructed to imagine how they would feel in the place of a target character who was observed experiencing painful heat to the hand, gave more evidence of empathic distress, both physiologically and verbally, than did subjects instructed to simply imagine how the other person feels. Cognitive processes 
obviously play a large part in this mode of affect arousal since it is the imaginative experiencing of events which is responsible for the emotional arousal. However, this process is important since it suggests that the empathic arousal of an individual can be relatively independent of the actual situation or emotional state of the target character.

By specifying these five modes of empathizing Hoffman is not attempting to define five different types of empathy. Rather, he is arguing that the experience of empathy may be modified by the development of the child's cognitive abilities. When Hoffman writes of a cognitive component, he is referring to a very basic ability.

The mature empathizer knows that the source of his affect is something happening to another person, and he has a sense of what the other person is feeling. The young child who lacks a self-other distinction does not have these cognitions. (Hoffman, 1977a, p. 3)

"Person permanence" is achieved by about twelve months of age and at this point the child is aware of others as being distinct from himself. Prior to this, the child must be unclear as to his own boundaries and his empathy would be immature as a result. By two or three years of age, the child knows that others have their own feelings and inner states independent of his own. By middle childhood, the child has developed to the point of understanding that others have personal identities and experiences beyond the immediate situation. Because of the fundamental role of cognition in empathy, Hoffman believes that this developmental sequence in the maturation of cognition must alter the very quality of the observer's empathic experience. With the awareness of the other as a separate and distinct individual comes the growing, 
reciprocal feeling of concern for the other in distress. The mature empathizer continues to respond empathically, feeling the other's distress, but now also feels compassion or "sympathetic distress" upon witnessing the other's suffering.

The development of sympathetic distress gives rise to the motivational component of Hoffman's model of empathy. The desire to aid another as a result of empathic arousal is not solely an egoistic motive to reduce empathic distress, but arises from the compassion generated along with the empathic response. The sympathic distress felt by the empathizer changes the aim of the person, from wanting to relieve his or her own distress, to a conscious desire to relleve the distress perceived in the other. This, then, is a more genuine prosocial motivation. Hoffman cites several studies (Geer \& Jarmecky, 1973; Latané and Dar1ey, 1970; Murphy, 1937; Weiss, et a1., 1973) demonstrating that individuals typically follow empathic arousal with altruistic acts, and in the event that no act of helping is made, the subjects report a continuation of arousal and feeling uncomfortable.

The support Hoffman musters to substantiate several features of his model is frequently anecdotal or correlational in nature. However, the logic of his argument, especially as it seeks to include findings of other areas of child development, is suggestive and certainly deserves additional research.

Developmental differences in empathy

There has been a good deal of attention directed to how empathy might change with age. In the past, many theorists have viewed empathy as a primitive method of communication which is lost as language is developed (Katz, 1963). Sullivan (1953) believed that empathy is a form of communication on a nonverbal level which originates in the 
relationship of the mother and the infant. In the infant it is most intense, he proposed, tending to decline with maturity. Based upon his observations, Sullivan concluded that very young infants react empathically to the moods of the adults who care for them.

Ernest Schachtel (in Katz, 1963) blamed the proposed decline in empathic abilities on the child's socialization. As an infant, the child uses the "proximity senses" of taste, touch, and smell. His or her direct participation in the environment fosters an empathic response to those around him or her. However, as the culture gives preference to the "distance senses" of sight and hearing, the child gradually loses the earlier reliance upon the proximity senses and becomes more detached and alienated from the environment. The use of standardized symbols, conventional categories, and images inhibits empathy until it finally atrophies.

Rather than declining developmentally, recent investigators have found that empathy, whether defined in the cognitive or emotional vein, increases with age. Ruderman (1961), using a pencil and paper test of empathy, found that empathy increased from ages nine to twelve. Iannotti (1977) found that role-taking ability, a cognitive skill related to empathy, increased with age. Kurdek and Rodgon (1975) found that perspective taking increases linearly from kindergarten through the sixth grade. Emotional empathy, as measured by the Feshbach and Roe (1968) procedure described earlier, has been found to increase between the ages of three and eight years (Fay, 1970; Feshbach \& Feshbach, 1969; Kuchenbecher, Feshbach, \& Pletcher, 1973).

The age at which a child can first empathize is of particular importance for the cognitive-type conceptualizations of empathy. Most 
cognitive theorists tend to accept Piaget's (1950) stages of development which state that a child younger than seven years of age is characteristically egocentric and cannot decenter adequately to empathize (e.g., Chandler \& Greenspan, 1972). Other theorists and researchers do not agree with the age demarcation set by the Piagetians. Borke (1972), for example, finds preschool children have remarkable empathic abilities. Waxler, Yarrow, and Smith (1977) found children as young as three years of age have some perspective taking skills, contrary to the findings of the Piagetian researchers.

Borke (1972) argues that the reason why the Piagetian cut-off age is too high and thus overestimates the age at which empathy is possible is that the tasks used in the research are too difficult for the youngsters, given the simplicity of their vocabularies. Rather than being unable to master the experimental tasks, the children are at a loss for words. A study by Greenspan, Barenboim, and Chandler (1976) is a clear example of how setting the task requirements too high can bias the task against younger children. In their experiment, children were asked to make affective judgments based upon complex and inconsistent social cues -- clearly a difficult task for a sixyear-old.

Sex differences in empathy

In their 1974 book on the psychology of sex differences, Maccoby and Jacklin reviewed thirty studies on empathy. They concluded that there is no consistent support for the belief that girls are more empathic than boys, contrary to the stereotype which says they are. This conclusion has been criticized by Hoffman (1977b) on the grounds that proper attention was not paid to the definition of empathy 
in each of the studies reviewed. Hoffman reorganized the studies and found that (a) in the six studies using a definition roughly equivalent to vicarious affective arousal, the females obtained higher scores, (b) in the studies where empathy was actually closer to simple recognition of the other's affect, females scored higher on two and there was no difference on the other five, and (c) in the remaining studies reviewed, the concept investigated was closer to social competence and the boys and girls were equally likely to obtain higher scores. Hoffman reviewed several additional studies, attempting to use more homogeneous classifications. Females tended to have higher scores than the males in all sixteen of the studies classified under vicarious affective arousal. In only three did the difference reach statistical significance, however, although an additional four approached significance. In those studies on recognition of affect, there was only a very slight tendency for girls to score higher than boys. Finally, in studies of cognitive and spatial perspective taking, boys showed a slight tendency to outscore the girls. Taken together, Hoffman concludes that if empathy is viewed as a vicarious affective experience, girls tend to be consistently more empathic than boys, although in individual studies the difference frequently fails to reach statistical significance.

Research on empathy and altruism: Cognitive perspectives

As noted earlier, research directed toward understanding the empathy-altruism relationship has tended to fall into one of two camps: cognitive and affective. The use of a cognitive definition of empathy has produced inconsistent findings as researchers attempt to predict prosocial behavior. Rubin and Schneider (1973) tested seven-year-olds 
on measures of communicative egocentrism (where the less egocentric child is considered more empathic) and moral development and then gave the children two opportunities to be altruistic by helping and donating. Success on the two cognitive measures was positively related to altruism.

Fry (1976) utilized a measure of social sensitivity which consisted of a videotape presentation of two adults in happy, angry, anxious, and sad interactions. Eleven-year-old children were asked to describe the feelings and motives of the adults. Fry found that social sensitivity and attitudes toward prosocial behavior were correlated with altruism and self-gratification in the expected directions, i.e., high social sensitivity and a positive attitude was predictive of high altruism while low social sensitivity and a negative attitude toward prosocial behavior predicted low altruism and high self-gratification. Waxler, Yarrow, and Smith (1977) investigated the relationship between perspective taking and altruism in three- to seven-year-olds and found that the ability to take the other's perspective failed to predict the prosocial measures of helping, sharing, or comforting. Their study did demonstrate, however, that very young children do have some ability to take the perspective of the other, a skill denied young children by the Piagetian theorists.

Another variety of cognitive definition centers on the role-taking abilities of the child. The question asked is whether the child has the capacity to step into another's shoes and see the world as the other sees it. The logic of testing role-taking skills relates to the earlier scenerio wherein the child observes someone in distress, and, by cognitively imagining what it would be like to experience that 
distress, is motivated to act altruistically. The empirical research on role-taking ability utilized by most researchers is one operationalized by Flavel1, Botkin, Fry, Wright, and Jarvis (1968). Flavell et al. list several separate tasks to measure role-taking skills. What the tasks all have in common is the requirement that the child must be able to understand that there may be a discrepancy between the information available to him/herself and information available to another person who arrives later and is not aware of essential details in the situation. The child's accuracy in predicting what the late arriver will conclude based upon available information is used as an index of the child's ability to put him/herself in the position of the other and view the situation from another perspective. Although some of the same role-taking measures are used in different studies, the results vary. Iannotti (1977) utilized two of these tasks to study the roletaking skills of seven- and ten-year-old boys and found that his correlational data supported the notion that the development of role taking is related to changes in altruism. In an earlier study, Iannotti (1975) had given six-year-old boys training in role taking and found that altruism was significantly greater following training. Krebs and Sturrup (1974), using the Flavell et al. (1968) role-taking tasks, found role-taking ability in seven- and eight-year-olds correlated significantly $(\underline{r}=.46, \underline{p}<.02)$ with a composite altruism score. In addition, they found positive, although nonsignificant correlations of role taking with component altruism scores and teachers' ratings of cooperative and prosocial behaviors. There have been failures, however, in attempts to find a reliable relationship between role taking and helping behavior. Emler and Rushton (1974), using the Flavell et al. 
(1968) technique, failed to find a relationship between role-taking skills and generosity. Similarly, Rushton and Wiener (1975) in a study with seven- and eleven-year-olds "failed to find any predictive utility for two different measures of role taking, again taken from Flavell et al. (1968), on three different measures of altruism" (Rushton, 1976, p. 903).

In summary, attempts to find a relationship between a cognitive, perspective-taking view of empathy and measures of prosocial behavior have produced inconsistent results. It is possible that some of the cognitive measures which have been successfully associated with prosocial behavior may include an implicit emotional component as well since the two are clearly not independent.

In his review of the literature, Rushton (1976) concluded that the research utilizing a purely cognitive conceptualization of empathy may be lacking an important element. "Further research using a wider range of role-taking tasks with particular emphasis on emotional role taking skills might prove useful" (Rushton, 1976, p. 903). Cognitive role taking is a skill which enables the child to understand, in an abstract manner, the experience of another. As discussed earlier, it does not involve a compelling motive for prosocial action. Résearch on empathy and altruism: Affective perspectives ${ }^{1}$

While only a few studies have been published which focus specifically on the more affective component of empathy, they have been quite consistent in demonstrating a positive association with prosocial behaviors. Aronfreed and Paskal (in Aronfreed, 1968) developed an experimental paradigm to study the assertion that a child's conditioned empathic response could enhance prosocial behavior. Their procedure consisted 
of three phases: (1) the child's negative affect was conditioned to the experimenter's expressive cues by pairing a loud noise with standardized distress cues, (2) the child was taught a lever-pulling response to terminate an aversive noise, and (3) the child was given an opportunity to respond altruistically to the distress cues of another child by pulling the noise-terminating lever. The heightened altruism of the experimental group of seven- and eight-year-old girls, relative to the performance of the several control groups, led Aronfreed (1968) to conclude that it was the experience of affective empathy in response to the distress cues of the other child, rather than the sheer information about the other's distress, which motivated the helpful acts. Unfortunately, Aronfreed and Paskal did not assess the children's empathic responses directly but simply inferred that their conditioning procedure had induced a disposition to respond empathically.

In a correlational study using the Feshbach and Roe (1968) empathy measure, Feshbach (1973) found empathy to be positively related to generosity in six- and eight-year-olds. Iannotti (1975), using a similar measure of empathy, found it to relate positively to sharing in six- and nine-year-olds. Leiman (1978) found that five- and sixyear-old children who were judged as showing empathic facial expressions upon seeing an actor lose his/her play materials (i.e., marbles) subsequently behaved more altruistically than did children judged to be relatively less empathic. Miller (1977) failed, however, to find a consistent relationship between the Feshbach and Roe measure of empathy and sharing in nine- and ten-year-olds. When one considers that the Feshbach and Roe technique was designed for use with children younger than Miller's sample, this failure to find an unambiguous relationship is not surprising. 
In an effort to combine the cognitive and affective dimensions of empathic responsiveness, Kameya (1976) provided role-taking training to groups of boys who differed in their relative capacity for empathy as measured by the Feshbach and Roe technique. Role-taking experiences were provided by encouraging the boys to act out stories using puppets, with special emphasis given to the thoughts and feelings of the other characters. Contrary to his predictions, Kameya found that his roletaking training had no effect upon the altruism of the high-empathy boys and produced inconsistent results with the low-empathy boys. In a related vein, Johnson (1975) contrasted the cognitive and affective perspective-taking skills of nine- to eleven-year-old children and concluded that the affective perspective-taking measure was a better predictor of one index of prosocial behavior, cooperation.

Finally, Feshbach (1978b) reported a pilot study in which empathy training was given over a ten-week interval to groups of disadvantaged children. Teachers' ratings revealed that the children in the condition which stressed both cognitive and affective aspects of empathy were significantly less aggressive and tended to behave more prosocially than non-participating peers.

Two conclusions can be drawn from the studies reviewed in the last two sections. First, the more "cognitive" indices of empathy relate inconsistently to measures of prosocial behavior. Where cognitive empathy does seem to lead to enhanced helping it is possible that an implicit affective component may be operative as well. Second, affective empathy seems to be a more consistent predictor of prosocial behavior than the predominantly cognitive versions, although there are very few studies from which to make such a judgment. 
A critique of the research on empathy and altruism in children

The preceding review of relevant literature reveals several gaps in our knowledge of the relationship between empathy and altruism. One problem is that previous studies with children have been largely correlational in nature such that the proposed causal link is obscured. A sample of comments from investigators of the empathy-altruism relationship reveals an awareness of the need to manipulate empathy and observe its impact upon the prosocial behavior of children. Iannotti (1975) points out that "although there has been some correlational evidence suggesting that empathy may be associated with.prosocial behaviors such as reduced aggression and altruism, there have been no attempts to manipulate empathy as an independent variable in order to ascertain its effect upon prosocial behaviors" (p. 24). Levine and Hoffman (1975) conclude that "in future studies, manipulation of empathic arousal and awareness within a situation calling for prosocial activity might clarify the relationship between empathy and prosocial behavior in young children" (p. 534).

An empathy manipulation approach has been used successfully with adults (e.g., Aderman \& Berkowitz, 1970; Batson et a1., 1978) but has not been attempted with children. The empathy manipulation was developed by Stotland (1969) and contrasts the responses of subjects asked to imagine themselves in the place of a target person with those of subjects asked merely to observe the target individual. A modified version of this approach was used in the present study. The manipulation of empathic arousal as an independent variable with a measure of altruism as a dependent variable is necessary to clarify the prior correlational work and directly test the proposal that empathic arousal elicits prosocial behavior in children. 
Another problem not sufficiently addressed by previous studies is the developmental question of whether the relationship between empathy and altruism is identical for both younger and older children. Young children (under six years of age) may lack the sophistication to act appropriately even though they may be empathically aroused. In contrast with studies involving somewhat older children (Barnett, Matthews, and Howard, 1979; Iannotti, 1975), several studies involving children less than 6 years of age found either no or low positive correlations between measures of empathy and various indices of prosocial behavior (Eisenberg-Berg \& Lennon, 1979; Iannotti, 1978; Kameya, 1976; Levine \& Hoffman, 1975) and positive associations between empathy and measures of antisocial behavior (Feshbach \& Feshbach, 1969; Murphy, 1937). In addition, Hoffman's (1977a) theoretical work suggests that some of the cognitive components of the empathic experience may not be fully developed in the very young child. This apparent developmental transition needs to be explored further.

A third question not answered by the studies reviewed above is the possibility of an interaction of dispositional empathy with the empathy arousing cues in the situation. While recognizing that there are situational influences which may arouse empathy (Krebs, 1975; Stotland, 1969) and that individuals may have varying capacities for empathy (Feshbach and Roe, 1968; Hoffman, 1975a; Mehrabian and Epstein, 1972), both of these have not been manipulated in the same design. It is likely that a highly empathic (or older) child may respond differently than a relatively less empathic (or younger) child in situations wherein the salience of empathic cues are varied. 


\section{Present Research}

\section{Overview}

The present study was conducted in two sessions. During the first session, the Feshbach and Roe (1968) empathy measure was administered to identify those children whose capacity for empathy was either high or low relative to their peers. In the second session, each child received 30 prize chips which were described as being redeemable for prizes at the conclusion of the study. The children were informed that some boys and girls from another classroom would not be able to participate and receive prizes, but that they could share some of their earnings with them if they wished. High and low empathic children from two age levels (preschoolers and kindergarteners; first and second graders) were randomly assigned to one of two conditions in which they were either (1) encouraged to focus on the feelings of the less fortunate others or (2) encouraged to think about the less fortunate others, but with no mention of feelings being made. The primary dependent variable was the number of prize chips donated, in private, by each child. A brief post-experimental questionnaire was administered to explore the child's feelings and comprehension of the situation during the donation interval.

\section{Hypotheses: Donation data}

The major hypotheses of the present study were as follows:

(1) A main effect was predicted for high versus low dispositional empathy. Highly empathic children were expected to be more altruistic than less empathic children. The correlational research cited earlier (c.f., Feshbach, 1973; Iannotti, 1974) generally points to this prediction and provided a major impetus for this study. 
(2) A main effect for High Empathy Arousal (HEA) versus Low Empathy Arousal (LEA) was expected. The technique utilized in the present investigation is similar to the approach developed by Stotland (1969) and used by others (Brehm \& Aderman, 1977; Regan \& Totten, 1975). In a related study with an adult sample, Aderman and Berkowitz (1970) found that the empathy-arousal group helped a needy other to a greater extent than did the control group. The HEA versus LEA comparison in the present study is the crucial test of the theoretical position of Hoffman (1976) and Feshbach (1973) that increasing empathic arousal in children will cause an increase in a1truistic behavior.

(3) A main effect for age level was predicted. In his review of altruism research with children, Bryan (1975) concluded that older children tend to share more in donation studies than do younger children. This developmental trend has been corroborated by more recent work as well (e.g., Barnett, King, \& Howard, 1979). Feshbach (1973) reports that older children also tend to be more empathic than younger children. This developmental increase in empathy might also lead one to predict that older children would share more of their prize chips than would younger children.

(4) No main effect of child's sex was predicted. Hoffman's (1977b) review suggested that girls are consistently more empathic than boys but that in individual studies the difference frequently fails to reach statistical significance. One might expect the greater empathy of girls to be associated with greater sharing than boys. A closer examination of the findings reported by Hoffman suggests, however, that the sex difference in empathy is more 
pronounced in children older than those in the present study. Finally, Bryan (1975) concluded that in donation studies involving young children, there has been no clear sex difference in sharing.

(5) An interaction was expected for high/low Dispositional Empathy and the HEA/LEA manipulation. The low empathy children were expected to remain unaffected by the HEA manipulation such that their donations would be approximately equal across the two conditions. The high empathy children, on the other hand, were expected to become empathically aroused in the HEA condition, but remain relatively unaroused in the LEA because of the absence of empathy cues. The donations of the highly empathic children were therefore predicted to differ significantly across the two conditions. As mentioned earlier, Kameya (1976) predicted a similar pattern of responsiveness to "cognitive" role-taking training by boys rated as high or low on the Feshbach and Roe (1968) measure of empathy. However, he found no effect for highs and inconsistent effects for lows with his cognitive role-taking approach. It was anticipated that the use of the more "affective" Stotland (1969) manipulation, wherein the children would (or would not) be encouraged to imagine themselves feeling the other's sadness, would be more successful.

(6) Finally, a three-way interaction was predicted for dispositional empathy, HEA/LEA, and age level. While the two-way interaction described in (5) was expected to be quite strong for the older children, studies by Feshbach and Feshbach (1969) and Levine and Hoffman (1975) have suggested that younger children (even the highly empathic ones) may not have the maturity necessary to transform empathic arousal into appropriate prosocial action. Therefore, although 
highly empathic younger children may be more aroused by the HEA manipulation than are low empathic younger children, it was expected that their levels of donating would be quite similar. In contrast, highly empathic older children were expected to be more empathically aroused and more charitable in the HEA condition than less empathic older children.

\section{Hypotheses: Questionnaire data}

While the brief questionnaire (see Appendix 4) administered at the end of the second session was largely exploratory in nature, the purpose of each question, as well as specific predictions made, should be noted.

(1) Question 1 was used as a manipulation check of the child's comprehension of the alternatives available during the donation request, i.e., whether the child was aware that he or she had the option to donate or not.

(2) Question 2 was intended as an "in task" assessment of each child's affective empathy. Since factors associated with or promoting heightened empathy should result in a child's experiencing more sadness about the needy others, the following predictions were made: (a) highly empathic children were expected to report feeling sadder than their relatively less empathic peers, (b) the children in the HEA condition were expected to feel sadder than the children in the LEA condition, and (c) since older children have been found to be more empathic than younger children, a main effect of age was also predicted.

(3) Question 3 was intended to assess each child's ability to infer the probable affect of the less fortunate others. Since even very young children have been shown to be aware of other individual's 
sadness (Borke, 1973; Sawin, 1979), it was expected that there would be little difference between the responses given to this question by the various groups of children. 
Method

Subjects and experimenters

A total of 88 males and 82 females from preschool through secondgrade classes in Manhattan, Kansas participated in the present investigation. The children were predominantly Caucasian and from middleclass backgrounds. Each child received parental permission to participate in the study. The parental permission form is presented in Appendix 1.

The younger group of children were from preschool and kindergarten classes and ranged in age from 45 months to 78 months $\underline{M}=5$ years, 4 months). The older group of children were first- and second-graders who ranged from 71 months to 111 months of age $(\underline{M}=7$ years, 1 month).

The first session was conducted by a male undergraduate assistant who was trained to administer the Feshbach and Roe (1968) empathy scale. The second session was conducted by a male graduate student in psychology who was blind as to the empathy level of each child. Apparatus, tests, and materials

The Feshbach and Roe (1968) measure of affective empathy was used to assess each child's level of dispositional empathy because it is the most widely used test of its kind for children between four and eight years of age. Reliability and validity measures have been satisfactory and are reported elsewhere (Feshbach, 1978a). As will be recalled from the earlier description, the measure consists of four pairs of slide sequences in which young children the same sex as the child are shown in situations designed to elicit four different emotions: happiness, sadness, anger, and fear. A brief narration describing the events in the slides, but devoid of affective 
terms, accompanies each slide sequence. For the complete script of the Feshbach and Roe (1968) slide sequences see Appendix 2. After viewing each slide sequence the child is asked "How do you feel?" or "Te11 me how you feel." The responses are taperecorded for future coding. If the child does not respond, the experimenter probes once more using only the statements above. While the two same-affect sequences are presented sequentially, the order of these affect pairs is randomized and counterbalanced. To prevent possible carry-over effects from the affect aroused during a prior sequence, one minute filler periods are inserted between affects. During these periods, the experimenter maintains a neutral dialogue with the child.

In the present study, the children's responses to each slide sequence were scored by two independent raters on a three-point scale: $0=$ an incorrect, instrumental, or task-irrelevant response; $1=a$ generally correct response on the positive-negative affective dimension; 2 = the correct, specific emotion. The raters obtained an interrater reliability of .93 on the individual responses, Disagreements were resolved by a third independent rater.

Median splits on the total empathy scores were used to divide the children into high and low empathy groups. While there was no significant difference between the empathy scores for boys and girls $(\underline{t}[168]=.45, \mathrm{~ns})$, the older group's scores were found to be significantly higher than those of the younger group $(\underline{t}[168]=3.89, \underline{p}<.001)$. Therefore, separate median splits were performed for each age level. ${ }^{2}$ Table 1 presents the empathy score means and standard deviations by child's sex and age level. 
Table 1: Empathy score descriptive statistics for sex and age level

$\begin{array}{lccc}\text { Group } & \underline{\mathrm{n}} & \underline{\mathrm{M}} & \underline{\mathrm{SD}} \\ \text { Younger } & 88 & 6.59 & 5.50 \\ \text { Males } & 40 & 6.70 & 5.46 \\ \text { Females } & 48 & 6.50 & 5.58 \\ \text { Older } & 82 & 9.51 & 4.25 \\ \text { Males } & 48 & 9.40 & 4.19 \\ \text { Females } & 34 & 9.68 & 4.39\end{array}$

Note: For the younger age level, the median split was at 7 . For the older age level, the median split was at 11 . Children whose scores fell on the median for their respective age group were excluded from all analyses which had High/Low dispositional empathy as a factor (see footnote 2). 
The second session required that each child participate in a task so that they could be awarded the prize chips. Although the information obtained was not relevant to this study, the Children's Personality Attributes Questionnaire or CPAQ (Spence \& Helmreich, 1977) was used as the task. This brief masculinity-femininity questionnaire requires the child to respond by indicating the degree to which he or she feels similar to another child described as engaging in traditionally masculine or feminine behaviors. The responses are obtained by having the child mark one of three boxes of increasing size indicating increasing agreement with the particular statement. The complete questionnaire and response scale appear in Appendix 3 .

Each child received 30 plastic prize chips after completing the CPAQ. The child was informed that each prize chip was worth one small prize. A metal, unmarked canister was provided so that the child might donate, in private, some of his or her prize chips. There were several prize chips left in the canister at all times to serve as evidence of prior donations.

Following the 60 second donation interval, the experimenter returned and administered a brief questionnaire which contained a manipulation check and other items relevant to the child's affect during the task. The post-experimental questionnaire and the "smiley face" scale which the children were trained to use to answer the last two questions are presented in Appendices 4 and 5, respectively.

\section{Procedure}

First session. In the first session, each child was escorted individually to the experimental room in the school building. When the child entered the experimenter said, 
Hi, my name is Cole. What's your name? Would you please sit here? The reason we asked you to come here today (child's name) is so that you can look at some pictures and tell me how you feel about them. Do you like to look at pictures? I am going to show you some pictures and tell you some stories about some children about the same age as you are.

The experimenter then presented the first slide sequence for the first affect. The experimenter taperecorded the last line of his script and the child's response to "How do you feel?" or "Tell me how you feel." The experimenter then continued with the second slide sequence of the first affect. After the second slide sequence for the first affect was completed, the experimenter continued, We have to let this light bulb cool off for a little bit because it gets very hot, so while we are waiting, let's just talk. The experimenter then turned the projector to "fan" and adjusted the slide tray to the next affect. During the one minute interval, the experimenter generated non-affect arousing fillers, such as: What kinds of things do you do at school? ... What about at recess? Do you have any brothers or sisters? ... What are their names and ages? ... What do you want to do when you grow up? The experimenter then continued with the first slide sequence for the second affect. The experimenter repeated this procedure for the remaining pairs of slide sequences. After the Feshbach and Roe measure had been completed, the experimenter said,

Thank you for helping me today. You did a really good job. The next person I need is (child's name). Would please go back to your classroom and show him(her) how to get here? Thank you. Goodbye. 
Second session. As in the first session, each child was escorted individually to the experimental room. When the child entered, the experimenter said,

Hi, my name is Jeff. Are you (expected child's name)? Today I am going to tell you about some children, ask you some questions, and have you color in this booklet. Let me show you how this works. Here is your crayon. I am going to be asking you some questions and you will mark your answers in the booklet. The questions do not have right or wrong answers. I want to know what you think about things, so be sure to mark what you really think. OK?

The CPAQ was administered at this time. After the CPAQ had been completed, the experimenter said to children in both the HEA and LEA conditions,

OK, good. For working on this game, I want you to have some prize chips. Here are 30 prize chips for you. Each prize chip is worth one small prize. I will give you your prizes for the prize chips when the experiment is over. There is one more thing I need to tell you. I will only be able to stay in your school for a short time, so some of the other children in other classes will not get to be in the experiment and will not get any prizes. The other children are about half boys and half girls and are all about the same age as you are. For children in the HEA condition only, the experimenter continued, 
Try to think about how the other children will feel when they don't get any prizes. Think of how you would feel if you were one of the other children who will not get any prizes. Try to feel how they will feel.

It should be noted that the LEA and the HEA conditions were identical except for the brief encouragement to empathize given to the children in the HEA condition.

For all of the children, the experimenter then said, If you would like to share any of your prize chips with the other children who will not get to be in the experiment, you can put some of your chips in this can.

The experimenter picked up the donation canister at this point and shook it to demonstrate that other children had already contributed. The experimenter further instructed the child,

You don't have to give any away, but you may if you want

to. I have to leave now to go to an important meeting. My assistant will be with you in about one minute to ask you some simple questions, so put any prize chips you want to give to the other children in the can while you are alone. Goodbye.

After the child had been allowed one minute to donate, the experimenter returned and explained to the child,

I still have some more time before my meeting starts so I thought I would come back to talk with you myself. Now let me put your prize chips in a safe place for you. The experimenter then wrote the child's name on a small paper sack and placed the child's remaining prize chips inside. The 
experimenter showed no response to the number of chips remaining, even if the child solicited a response. The experimenter then told the child,

When I am finished with this experiment, I will come to your classroom and give you your prizes, ok? That way I can give out the prizes to everyone at the same time. Before you go back to your class, I want to ask you a few more questions.

At this point, the experimenter administered the brief postexperimental questionnaire (see Appendix 4). When it was completed, the experimenter said,

Thanks for helping me today. You did a very good job.

The next person I need to talk to is (child's name). Would you please show him(her) how to get here? Thank you.

Goodbye.

\section{Sumnary of the procedure}

In clarifying the procedure, three points should be reiterated. First, the sole purpose of the first session was to obtain each child's empathy score. These scores were the basis for a high/low empathy median split for each age level. Second, each child received 30 prize chips in the second session simply for participating in the experiment. Highs and lows from each age level were exposed to either an empathy arousing instructional set (HEA) or an instructional set in which the needy others were described but the empathy cues were relatively less salient (LEA). An opportunity to share, in private, was then provided. Third, following the donation interval, each child responded to a brief questionnaire which contained a manipulation check and provided additional information regarding the child's affective state during the experiment. 


\section{Results}

Unexpectedly, the distribution of scores for the primary dependent variable, number of prize chips donated, was very skewed with $46 \%$ of the children failing to donate. Figure 1 presents the donation distribution for the entire sample. Because of the extreme non-normality of the data, the analysis of variance test of significance was deemed inappropriate. ${ }^{3}$

The Wilson (1956) test of significance was utilized in analyzing the donation data. ${ }^{4}$ The wilson test is a non-parametric technique, similar to the standard $x^{2}$ test, which allows for individual tests of main effects and interactions. The logic of the test follows in three steps: (1) the median score on the dependent measure is determined, (2) scores in each cell are reduced to simply the number of subjects who scored on or above the median and those who scored below the median, (3) a $x^{2}$ test is then performed to determine if the proportion of subjects observed above and below the median differs significantly across conditions. To test specific main effects and interactions, the cells are collapsed to form the comparison of interest. Table 2 presents the number of children donating above and below the median in each cell. Although cell means are not used in the Wilson test, they have been included in Table 2 for clarity. Table 2a presents the sumary data for the four main effects. Table 3 presents the results of the donation data analyses.

Donation data. The results of the donation data analyses are presented below in the order that the specific predictions (see page 27) were listed. 
Figure 1. Distribution of Donations

for the Total Sample

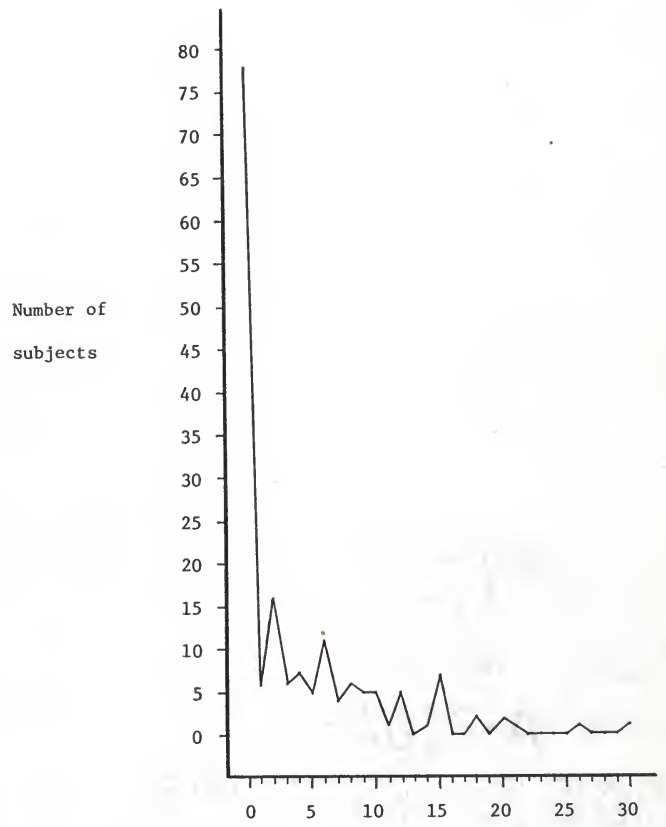

Number of prize chips donated 
Table 2. Mean Number of Prize Chips Donated and Number of Subjects Above and Below the Median.

HEA

Age Level-Empathy Disposition

$$
\begin{gathered}
\text { Young-ligh } \\
\text { male } \\
\text { female } \\
\text { Young-Low } \\
\text { male } \\
\text { female } \\
\text { old-High } \\
\text { male } \\
\text { female } \\
\text { old-Low } \\
\text { male } \\
\text { female }
\end{gathered}
$$

Subjects Above/Below

Median*

Mean

$\begin{array}{cc}10 / 13 & 3.17 \\ 5 / 6 & 4.18 \\ 5 / 7 & 2.25 \\ 10 / 11 & 3.57 \\ 4 / 5 & 4.67 \\ 6 / 6 & 2.75 \\ 17 / 5 & 6.32 \\ 12 / 0 & 7.08 \\ 5 / 5 & 5.40 \\ 12 / 6 & 5.00 \\ 8 / 3 & 5.82 \\ 4 / 3 & 3.71\end{array}$

LEA

Age Leve1-Empathy Disposition

$\begin{array}{ccc}\text { Young-High } & 8 / 12 & 2.10 \\ \text { male } & 4 / 6 & 2.80 \\ \text { female } & 4 / 6 & 1.40 \\ \text { Young-Low } & 6 / 16 & 4.09 \\ \text { male } & 3 / 7 & 3.40 \\ \text { female } & 3 / 9 & 4.67 \\ \text { Old-High } & 9 / 8 & 3.65 \\ \text { male } & 6 / 4 & 4.80 \\ \text { female } & 3 / 4 & 2.00 \\ \text { 01d-Low } & 9 / 9 & 4.06 \\ \text { male } & 6 / 6 & 4.25 \\ \text { female } & 3 / 3 & 3.67\end{array}$

*The median fell between 1 and 2 prize chips. 
Table 2a. Mean Number of Prize Chips Donated and Number of Subjects Above and Below the Median for the Tests of Main Effects

Subjects Above/Below

Variable

Mean

Empathy Disposition

High

$44 / 38$

3.85

Low

$37 / 42$

4.15

Condition

HEA

$49 / 35$

4.63

LEA

$32 / 45$

3.45

Age Level

old

$47 / 28$

4.74

Young

$34 / 52$

3.41

Sex

Male

$48 / 37$

4.73

Female

$33 / 43$

3.31 
Table 3. Wilson Analysis of the Donation Data

$\begin{array}{lccc}\text { Source } & \chi^{2} & \text { df } & \text { P } \\ \text { Dispositional Empathy (DE) } & .749 & 1 & \text { n.s. } \\ \text { HEA/LEA (H/L) } & 4.522 & 1 & <.05 \\ \text { Age Level (AL) } & 8.575 & 1 & <.01 \\ \text { Child's Sex (CS) } & 2.733 & 1 & \text { n.s. } \\ \text { DE } \times \text { H/L } & -.093^{*} & 1 & \text { n.s. } \\ \text { DE } \times \text { AL } & -.043 * & 1 & \text { n.s. } \\ \text { DE } \times \text { CS } & .642 & 1 & \text { n.s. } \\ \text { H/L } \times \text { AL } & .056 & 1 & \text { n.s. } \\ \text { H/L X CS } & .691 & 1 & \text { n.s. } \\ \text { AL } \times \text { CS } & .482 & 1 & \text { n.s. } \\ \text { DE } \times \text { H/L } \times \text { AL } & .617 & 1 & \text { n.s. } \\ \text { DE } \times \text { H/L } \times \text { CS } & .302 & 1 & \text { n.s. } \\ \text { DE } \times \text { AL } \times \text { CS } & .959 & 1 & \text { n.s. } \\ \text { H/L } \times \text { AL } \times \text { CS } & .894 & 1 & \text { n.s. } \\ \text { DE } \times \text { H/L } \times \text { AL } \times \text { CS } & -.198 * & 1 & \text { n.s. }\end{array}$

*Note: As with many computer programs for the analysis of variance, when the magnitude of an interaction is extremely sma11, the estimate obtained by the lilson test may be negative due to the subtraction process used to calculate the interaction values. 
(1) Contrary to prediction, Dispositional Empathy, as measured by the Feshbach and Roe (1968) empathy scale, was not found to be associated with the children's donations. Highly empathic children actually donated slightly fewer prize chips than did their relatively less empathic peers but the difference between highs and lows did not approach statistical significance.

(2) As predicted, there was a significant main effect of HEA/LEA; children in the HEA condition showed a higher incidence of donating than did the children in the LEA condition.

(3) As predicted, a significant main effect of Age Level was also found. Older children showed a higher incidence of donating than did the younger children.

(4) As expected, there was no main effect for sex of subject on the Wilson test, with the proportions of boys and girls above and below the median not statistically different from one another. ${ }^{5}$

(5) Contrary to prediction, no interaction of Dispositional Empathy and HEA/LEA was found.

(6) Finally, the expected three-way interaction of Dispositional Empathy, HEA/LEA, and Age Level failed to reach statistical significance. Post-experimental questionnaire. (See Appendix 4 for a complete listing of questionnaire items.) Question 1 served as a manipulation check. Ninety-five percent of the children responded that they knew that they could donate if they wished but were not required to do so. of the eight children who answered incorrectly, seven were from the younger age level and were evenly distributed across the experimental conditions; all of these children were retained in the analyses. 
Table 4 presents a summary of the responses to Questions 2 and 3. These responses were analyzed with 2 (Dispositional Empathy) $x$ 2(HEA/LEA) $\times 2$ (Age Leve1) $\times 2$ (Sex of Child) analyses of variance. Summaries of these analyses are presented in Tables 5 and 6 .

The results for the specific predictions for Question 2 (see page 30 ) are as follows:

(1) Contrary to expectation, Dispositional Empathy was not found to be associated with responses to Question 2. Highly empathic children did not report feeling significantly sadder $(\underline{M}=3.72)$ than did the less empathic children $(\underline{M}=3.41)$.

(2) As predicted, children in the HEA condition reported feeling sadder than did the children in the LEA condition. (Means are presented in the "Total" column of Table 4.)

(3) As predicted, older children reported feeling sadder than did the younger children $\underline{\underline{M}}=3.99$ and 3.16 , respectively).

(4) There was no significant main effect for Sex of Child; boys and girls had the identical mean score of 3.56 on this question. Although not predicted, a significant interaction of Age Level and HEA/LEA was found on this question. A subsequent Newman-Keuls analysis revealed that the interaction was due primarily to the children in the Young-LEA group $(\underline{\mathbb{N}}=2.65)$ who reported being significantly less sad than children in the foung-HEA $(\underline{M}=3.64)$, 01d-LEA $(\underline{M}=3.90)$, and 01d-HEA $(\underline{M}=4.07)$ groups, who did not differ significantly from one another. This finding is understandable since one would expect the children in the Young-LEA group to be the least empathic and, thus, the least saddened by the plight of the unfortunate others. However, the interaction probably adds little additional information 
Table 4. Mean Responses to Questions 2 and 3 by Condition.

\begin{tabular}{|c|c|c|c|c|}
\hline \multirow[b]{2}{*}{ Age level - Empathy disposition } & \multicolumn{2}{|c|}{ Question 2} & \multicolumn{2}{|c|}{ Question 3} \\
\hline & $\underline{\mathrm{HEA}}$ & $\underline{\text { LEA }}$ & HEA & LEA \\
\hline Young-High & 3.96 & 2.85 & 4.96 & 4.90 \\
\hline male & 3.82 & 2.40 & 4.91 & 4.80 \\
\hline female & 4.08 & 3.30 & 5.00 & 5.00 \\
\hline Young-Low & 3.29 & 2.55 & $4 \cdot 48$ & 4.14 \\
\hline male & 3.56 & 2.20 & 4.11 & 3.60 \\
\hline female & 3.08 & 2.83 & 4.75 & 4.58 \\
\hline Old-High & 3.91 & 4.18 & 4.77 & 4.82 \\
\hline male & 4.08 & 4.20 & 4.67 & 4.80 \\
\hline female & 3.70 & 4.14 & 4.90 & 4.86 \\
\hline 01d-Low & 4.22 & 3.78 & 4.67 & 4.50 \\
\hline male & 4.00 & 4.00 & 5.00 & 4.42 \\
\hline female & 4.57 & 3.33 & 4.14 & 4.67 \\
\hline 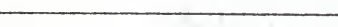 & & & - & \\
\hline Total & 3.83 & 3.27 & 4.73 & 4.57 \\
\hline
\end{tabular}

Question 2: How did you feel when I told you about the other children who wouldn't get any prizes?

Question 3: How did you think the other children would feel when they didn't get any prizes? 
Table 5. Analysis of Responses to Question 2.

\begin{tabular}{|c|c|c|c|c|}
\hline Source & $\underline{\mathrm{df}}$ & $\underline{\mathrm{MS}}$ & $\underline{\mathbf{F}}$ & p \\
\hline Dispositional Empathy (DE) & 1 & 2.835 & 1.868 & n.s. \\
\hline HEA/LEA (H/L) & 1 & 11.002 & 7.123 & $<.01$ \\
\hline Age Leve1 (AL) & 1 & 27.384 & 17.728 & $<.001$ \\
\hline Child's Sex (CS) & 1 & 0.347 & 0.225 & n.s. \\
\hline $\mathrm{DE} \times \mathrm{H} / \mathrm{L}$ & 1 & 0.189 & 0.122 & n.s. \\
\hline $\mathrm{DE} \times \mathrm{AL}$ & 1 & 1.992 & 1.290 & n.s. \\
\hline $\mathrm{DE} \times \mathrm{CS}$ & 1 & 0.264 & 0.171 & n.s. \\
\hline $\mathrm{H} / \mathrm{L} \times \mathrm{AL}$ & 1 & 7.427 & 4.808 & $<.05$ \\
\hline $\mathrm{H} / \mathrm{L} \times \mathrm{CS}$ & 1 & 1.020 & 0.660 & n.s. \\
\hline $\mathrm{AL} \times \mathrm{CS}$ & 1 & 2.095 & 1.356 & n.s. \\
\hline $\mathrm{DE} \times \mathrm{H} / \mathrm{L} \times \mathrm{AL}$ & 1 & 2.984 & 1.932 & n.s. \\
\hline $\mathrm{DE} \times \mathrm{H} / \mathrm{L} \times \mathrm{CS}$ & 1 & 0.492 & 0.319 & n.s. \\
\hline $\mathrm{DE} \times \mathrm{AL} \times \mathrm{CS}$ & 1 & 1.286 & 0.833 & n.s. \\
\hline $\mathrm{H} / \mathrm{L} \times \mathrm{AL} \times \mathrm{CS}$ & 1 & 4.003 & 2.591 & n.s. \\
\hline $\mathrm{DE} \times \mathrm{H} / \mathrm{L} \times \mathrm{AL} \times \mathrm{CS}$ & 1 & 2.492 & 1.613 & n.s. \\
\hline Error & 145 & 1.545 & & \\
\hline
\end{tabular}


Table 6. Analysis of Responses to Question 3.

\begin{tabular}{|c|c|c|c|c|}
\hline Source & $\underline{\mathrm{df}}$ & $\underline{\mathrm{MS}}$ & $\underline{F}$ & $\mathrm{p}$ \\
\hline Dispositional Empathy (DE) & 1 & 7.252 & 11.176 & $<.001$ \\
\hline HEA/LEA (H/L) & 1 & 0.595 & 0.917 & n.s. \\
\hline Age Leve1 (AL) & 1 & 0.355 & 0.547 & n.s. \\
\hline Child's Sex (CS) & 1 & 1.832 & 2.824 & n.s. \\
\hline $\mathrm{DE} \times \mathrm{H} / \mathrm{L}$ & 1 & 0.598 & 0.922 & n.s. \\
\hline $\mathrm{DE} \times \mathrm{AL}$ & 1 & 1.915 & 2.951 & n.s. \\
\hline $\mathrm{DE} \times \mathrm{CS}$ & 1 & 0.174 & 0.268 & n.s. \\
\hline $\mathrm{H} / \mathrm{L} \times \mathrm{AL}$ & 1 & 0.278 & 0.428 & n.s. \\
\hline $\mathrm{H} / \mathrm{L} \times \mathrm{CS}$ & 1 & 0.951 & 1.465 & n.s. \\
\hline $\mathrm{AL} \times \mathrm{CS}$ & 1 & 2.688 & 4.142 & $<.05$ \\
\hline $\mathrm{DE} \times \mathrm{H} / \mathrm{L} \times \mathrm{AL}$ & 1 & 0.065 & 0.101 & n.s. \\
\hline $\mathrm{DE} \times \mathrm{H} / \mathrm{L} \times \mathrm{CS}$ & 1 & 1.223 & 1.884 & n.s. \\
\hline DE $x$ AL $x$ CS & 1 & 3.145 & 4.860 & $<.05$ \\
\hline $\mathrm{H} / \mathrm{L} \times \mathrm{AL} \times \mathrm{CS}$ & 1 & 0.116 & 0.179 & n.s. \\
\hline $\mathrm{DE} \times \mathrm{H} / \mathrm{L} \times \mathrm{AL} \times \mathrm{CS}$ & 1 & 0.661 & 1.018 & n.s. \\
\hline Error & 145 & 0.649 & & \\
\hline
\end{tabular}


beyond that obtained in the two main effects because of the likelihood that the responses of the 01d-HEA group were influenced by a ceiling effect.

Scores on Question 3 were consistently high (overall $\underline{M}=4.66$ out of a possible 5) indicating that most children thought the children who would not get any prizes would be extremely sad. Even with the restricted range of responses on this question, an analysis of variance revealed a significant main effect for dispositional empathy. Highly empathic children indicated that the less fortunate others would feel sadder $(\underline{M}=4.87)$ than did the less empathic children $(\underline{M}=4.43)$. Since there was no disposition effect for Question 2, the more affective empathy index, this finding is problematic and will be addressed more fully in the discussion section of this paper. Table 6 shows that there were two interactions which also reached statistical significance. Newman-Keuls analyses revealed that both interactions were primarily due to the younger, low empathy boys who rated the feelings of the less fortunate others significantly less unhappy $(\underline{M}=3.60)$ than did all other groups (overall $\underline{M}=4.77$ for the remaining seven groups). These two interactions appear uninterpretable. 


\section{Discussion}

In the present study, children in the HEA condition were more altruistic than were the children in the LEA condition. Moreover, even though all of the children were aware that the less fortunate others would be quite sad (Question 3), the children in the HEA condition felt sadder than the children in the LEA condition (Question 2). It would appear, therefore, that the instructions to vicariously experience the feelings of the needy others effectively aroused an empathic response and subsequently heightened the child's charitable behavior. This pattern of findings is consistent with that reported in studies manipulating empathic arousal in adults (Aderman \& Berkowitz, 1970; Coke, Batson, \& McDavis, 1978; Krebs, 1975) and provides support for the theoretical assertion (Feshbach, 1973; Hoffman, 1976) that arousing empathy in young children may motivate helping behavior.

In addition, older children were found to be more altruistic than younger children. This effect has been found consistently in donation studies involving children (Bryan, 1975) but the explanation for this developmental trend remains unclear. There are probably many reasons why older children might exhibit heightened levels of prosocial behavior, such as a greater awareness of the "norm of responsibility" (Berkowitz \& Daniels, 1964) or enhanced moral reasoning levels relative to younger children (Kohlberg, 1963). However, the finding in the present study that older children reported being sadder, that is, more empathically aroused, than did the younger children, is at least consistent with the assertion that a greater empathic responsivity in older children may contribute to their tendency to behave more altruistically. 
There were apparent1y two major problems encountered in the present study. The first problem concerns the highly skewed nature of the distribution of donations (requiring the use of non-parametric statistical tests). Although the donation paradigm is often used in studies of prosocial behavior (see reviews by Bryan [1975] and Rushton [1976]), few studies have involved such young children. Perhaps the donation of task earnings is a rather unusual behavior for young children. The large number of children who did not donate at all (46\%) would lead one to suspect that the helping measure might have been more effective had it been made more congruent with the children's regular repertoire of behaviors.

The second problem involved the assessment of dispositional empathy. None of the predicted main or interaction effects involving the dispositional empathy factor were found to approach statistical significance with respect to donations. There are several reasons why this result might have been obtained. Leiman (1978) has noted that the Feshbach and Roe (1968) scale (1) is highly dependent on verbal-cognitive skills, (2) measures voluntary responses which are vulnerable to demand characteristics of the experimental situation, (3) requires children to repeatedly report their own emotions, which may prompt a child to respond too quickly to "speed things along," and (4) perhaps unrealistically assumes that children will form an emotional relationship with a story character and that this type of emotional matching is generalizable to interactions with peers. The criticism that the Feshbach and Roe measure may be unduly influenced by cognitive skills is supported by the finding in the present study that responses to the Feshbach and Roe were more closely associated 
with responses to Question 3, the cognitive perspective-taking item, than with responses to Question 2, the "in task" measure of affective empathy. If, in fact, the Feshbach and Roe (1968) technique is primarily a measure of the child's cognitive perspective-taking skills, it is not surprising that it was ineffective in predicting helping behavior.

The consistent responses to Question 3 indicate that even very young children can demonstrate an awareness of another's sadness, corroborating an earlier finding by Borke (1973). Moreover, the pattern of donations across conditions demonstrates that encouraging young children to empathize with the feelings of less fortunate others may enhance helping behavior. This finding, in addition to being supportive of the empathy arousal-altruism hypothesis, also appears to have important implications for child-rearing. Hoffman (1975b) reported a significant positive correlation between fifth-graders' altruism toward their peers and parental use of discipline techniques which involve focusing the child's attention upon the feelings of others. This association, along with the findings of the present study, supports the notion that adult intervention which directs the child's empathic responsiveness to the feelings of others in discipline and non-discipline situations may promote prosocial behavior in young children. Moreover, since no interaction of HEA/LEA and age level was found, the present study suggests that the intervention of a parent may be necessary to activate even the six- and seven-year-old child's capacity for empathy. It would seem, therefore, that discipline techniques which emphasize others' feelings, and appeals to help which similarly induce empathic arousal, may be useful methods adults can utilize to promote prosocial behaviors in young children. 
Additional studies of children's empathy and helping behaviors are needed to investigate the questions left unanswered by the present experiment. Better measures of dispositional empathy in young children, perhaps using facial expressions or other nonverbal cues, are clearly needed. In addition, the study of naturally occurring helping behaviors may avoid the "floor effect" encountered in the present study while also enhancing external validity.

Future research should also explore the effect of having a less fortunate other immediately present in the situation, rather than merely described as in the present study. This would 1ikely have the effect of heightening the salience of the empathy cues for the potential helper. The work of Feshbach and Roe (1968) and others (Krebs, 1975; Stotland, 1969) suggests that the sex and relative similarity of the target individual may be important variables in this type of encounter. In addition, little is known regarding the power of a peer to induce empathic arousal; perhaps children could be trained to facilitate empathizing in their peers.

Finally, future studies should investigate the extent to which the ability to transform motives, such as empathic arousal, into action requires additional helping-relevant skills. Children (and adults) are likely to vary in (1) their relative ability to generate a range of possible helping responses and to select the most appropriate one, and (2) their level of competence and/or assertiveness to actually follow through once the appropriate response is chosen. An extremely empathy-arousing situation may simply debilitate (or yield avoidance behavior in) a person, even a highly empathic one, who lacks these additional skills. 
Clearly, much work remains to be done before a comprehensive understanding of the role of empathy in the development and expression of prosocial behavior is possible. However, the present study has shown that empathic arousal may provide an important motivational construct for future theories of altruism in young children. 


\section{Footnotes}

${ }^{1}$ Affective empathy implies emotional arousal in the empathic observer. This has led to several investigations of the physiological component of empathy. Because these studies have not involved children, they will not be considered in the text of the present paper. However, they are briefly reviewed below for interested readers.

When dealing with emotional arousal, two components can be studied. The emotion can be considered to have a subjective element and a physiological component. "The ideal measure of an empathic response," says Hoffman (1977b), "would include evidence that a) affect has been aroused in the observer, and b) the quality and direction of the affect correspond to those experienced by the person being observed" (p. 713). Physiological measures of empathy, while meeting the first criterion, fail on the second. Investigators hoping to benefit from the use of these physiological techniques have studied changes in galvanic skin response, vasoconstriction, and heart rate (e.g., Krebs, 1975), and palmar sweating (Stotland, 1969). Berger (1962) used physiological measures in a paradigm to condition empathy, but noted that, while increased GSR may indicate empathy, some sadistic individuals may enjoy another person's pain and show a similar GSR reaction. Hoffman (1977b) adds that the physiological measure may simply reflect the individual's startle response to the movement of another, or may be a response to the noxious stimulus and not the observed person's distress cues. In addition, one study found a negative relationship between the magnitude of physiological arousal and the introspective reports of the intensity of feelings of distress the subjects experienced as they watched a model receive shocks (Craig \& Lowery, 1969). 
There have been no physiological studies done with children to address the empathy-altruism relationship, but in spite of the above problems, studies have been conducted with adults. Krebs (1975) found that empathy and altruism are positively related in college students. Using the measures listed above, he manipulated the similarity of the target character to the subject, and the amount of pleasure or pain the target person experienced. "When required to make a choice between helping themselves at a cost to the performer or helping the performer at a cost to themselves, the subjects who reacted most empathically behaved most altruistically" (Krebs, 1975, p. 1134). Subjects who believed the performer was experiencing greater pleasure or pain exhibited greater psychophysiological reactions than those subjects who did not. Subjects who believed they were similar to the performer empathized more than those who believed they were different from the performer.

2 The statistics reported in the results section are based upon the scores of the 170 boys and girls who participated in the study with the following exception. In the analysis of the primary dependent variable (i.e., number of prize chips donated) 3 boys and 6 girls fell on the "empathy" median when their respective age levels were divided into highs and lows. Since these nine children were neither highs nor lows, they were excluded from the analysis of the donation data and all subsequent analyses involving high/low dispositional empathy.

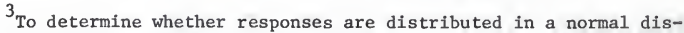
tribution, Hays (1963) suggests a simple $\chi^{2}$ goodness-of-fit test. The distribution of donations differed significantly from normal 
$\left(\chi^{2}=317.52, P^{<} .001\right)$ and even after the $X^{\prime}=\sqrt{X+.5}$ transformation suggested by Winer (1971) the distribution remained markedly nonnormal $\left(x^{2}=267.90, p<.001\right)$. Although the analysis of variance test of significance is quite robust, the extreme non-normality of the distribution made the use of a parametric statistic inappropriate.

${ }^{4} \mathrm{~A}$ recent textbook of research methods in developmental psychology (Achenbach, 1978) suggests that the Wilson test is appropriate for extremely skewed distributions. Wilson's technique has been used regularly in many areas of behavioral research.

${ }^{5}$ Although the difference between the means for boys and girls is actually greater than the difference between the means for HEA and LEA, the Wilson test (which reduces the impact of extreme scores contributing to mean differences) resulted in a nonsignificant main effect for sex. 


\section{References}

Achenbach, T. M. Research in developmental psychology: Concepts, strategies, methods. New York: The Free Press, 1978. Aderman, D., \& Berkowitz, L. Observational set, empathy, and helping. Journal of Personality and Social Psychology, 1970, 14, 141-148. Archer, R., Foushee, H. C., \& Davis, M. H. Empathy in the courtroom; a person-situation interaction. University of Texas at Austin, unpublished manuscript, 1977.

Aronfreed, J. Conduct and conscience: The socialization of internalized control over behavior. New York: Academic Press, 1968. Aronfreed, J. The socialization of altruistic and sympathetic behavior: Some theoretical and experimental analyses. In J. Macaulay and L. Berkowtiz (Eds.), Altruism and helping behavior. New York: Academic Press, 1970.

Barnett, M. A., \& Bryan, J. H. Effects of competition with outcome feedback on children's helping behavior. Developmental Psychology, $1974,10,838-842$.

Barnett, M. A., King, L. M., \& Howard, J. A. Inducing affect about self or other: Effects on generosity in children. Developmenta1 Psychology, 1979, 15, 164-167.

Barnett, M. A., Matthews, K. A., \& Howard, J. A. The relationship between competitiveness and empathy in six- and seven-year-olds. Developmental Psychology, 1979, 15, 221-222.

Batson, C. D., Darley, J. M., \& Coke, J. S. Altruism and human kindness: Internal and external determinants of helping behavior. In L. Pervin and M. Lewis (Eds.), Internal and external determinants of behavior. New York: P1enum, in press. 
Berger, S. M. Conditioning through vicarious instigation. Psychologica1 Review, $1962,69,450-466$. Berkowitz, L., \& Daniels, L. Affecting the salience of the social responsibility norm: Effects of past help on the response to dependency relationships. Journal of Abnormal and Social Psycho$\underline{\operatorname{logy}}, 1964, \underline{68}, 275-281$.

Borke, H. Chandler \& Greenspan's "Ersatz egocentrism:" a rejoinder. Developmenta1 Psychology, 1972, ㄱ, 107-109.

Borke, H. The development of empathy in Chinese and American children between three and six years of age: A cross-cultural study. Developmental Psychology, 1973, 9, 102-10s.

Brehm, S. S., \& Aderman, D. On the relationship between empathy and the actor versus observer hypothesis. Journal of Research in Personality, 1977, 11, 340-346.

Bryan, J. H. Children's cooperation and helping behaviors. Chicago: University of Chicago Press, 1975. Bryan, J. H., \& London, P. Altruistic behavior by children. Psychologica1 Bulletin, 1970, 73, 200-211.

Buss, A. H. The psychology of aggression. New York: Wiley, 1961. Chandler, M. J., \& Greenspan, S. Ersatz egocentrism: A reply to H. Borke. Developmental Psychology, 1972, 7, 104-106.

Coke, J. S., Batson, C. D., \& McDavis, K. Empathic mediation of helping: A two stage model. Journal of Personality and Social Psychology, 1978, 36, 752-766.

Craig, K. D., \& Lowery, H. J. Heart rate components of conditioned vicarious autonomic responses. Journal of Personality and Social Psychology, 1969, 11, 381-387. 
Eisenberg-Berg, N., \& Lennon, R. Altruism and the assessment of empathy in the preschool years. Paper presented at the bienniel meeting of the Society for Research in Child Development, San Francisco, March, 1979.

Emler, N. P., \& Rushton, J. P. Cognitive-developmental factors in children's generosity. British Journal of Social and Clinical Psychology, 1974, 13, 277-281.

Fay, B. The relationships of cognitive moral judgment, generosity, and empathic behavior in six- and eight-year-old children. University of California, Los Angeles, Unpublished doctoral dissertation, 1970 .

Feshbach, N. D. Empathy: An interpersonal process. Paper presented at the meeting of the American Psychological Association, Montreal, August, 1973.

Feshbach, N. D. Empathy in children: Some theoretical and empirical considerations. The Counseling Psychologist, 1975, $\underline{5}, 25-30$.

Feshbach, N. D. Studies of empathic behavior in children. In B. A. Maher (Ed.), Progress in experimental personality research (Vol. 8). New York: Academic Press, 1978. (a)

Feshbach, N. D. Empathy training: A field study in affective education. Paper presented at the meeting of the American Educational Research Association, Toronto, Canada, March, 1978.

Feshbach, N. D., \& Feshbach, S. The relationship between empathy and aggression in two age groups. Developmental Psychology, 1969, 1, 102-107.

Feshbach, N. D., \& Roe, K. Empathy in six- and seven-year-olds. Child Development, $1968, \underline{39}, 133-145$. 
Flavel1, J. H., Botkin, P. T., Fry, C. L., Jr., Wright, J. W., \& Jarvis, P. E. The development of role-taking and communication skills in young children. New York: Wiley, 1968.

Fry, P. S. Children's social sensitivity, altruism, and self-gratification. The Journal of Social Psychology, 1976, 98, 77-88.

Geer, J. H., \& Jarmecky, L. The effect of being responsible for reducing another's pain on subject's response and arousal. Journal of Personality and Social Psychology, 1973, 26, 232-237. Greenspan, S., Barenboim, C., \& Chandler, M. J. Empathy and pseudoempathy: The affective judgments of first- and third-graders. The Journal of Genetic Psychology, 1976, 129, 77-88. Harris, M. B., \& Siebe1, C. E. Affect, aggression, and altruism. Developmental Psychology, 1975, 11, 623-627.

Hays, W. L. Statistics for psychologists. New York: Holt, 1963. Hoffman, M. L. Developmental synthesis of affect and cognition and its implications for altruistic motivation. Developmental Psychology, 1975, 11, 607-622. (a)

Hoffman, M. L. Altruistic behavior and the parent-child relationship. Journal of Personality and Social Psychology, 1975, $\underline{31}$, 937-943. (b)

Hoffman, M. L. Empathy, role-taking, guilt, and development of altruistic motives. In T. Lockona (Ed.), Moral development and behavior: Theory, research, and social issues. New York: Holt, Rinehart, and Winston, 1976.

Hoffman, M. L. A three component model of empathy. Paper presented at the meeting of the Society for Research in Child Development, New Orleans, March, 1977. (a) 
Hoffman, M. L. Sex differences in empathy and related behaviors. Psychological Bulletin, 1977, 84, 712-722. (b)

Huckaby, L. M. A developmental study of the relationship of negative moral-social behaviors to empathy, to positive social behaviors, and to cognitive moral judgment. University of California, Los Angeles. Unpublished doctoral dissertation, 1971.

Iannotti, R. J. Empathy as a motivator of altruistic behavior.

Paper presented at the annual meeting of the American Psychological Association, New Orleans, August, 1974.

Iannotti, R. J. The nature and measurement of empathy in children. The Counseling Psychologist, 1975, 5, 21-25.

Iannotti, R. J. A longitudinal investigation of role-taking, altruism, and empathy. Paper presented at the meeting of the Society for Research in Child Development, New Orleans, March, 1977.

Isen, A. M. Success, failure, attention and reaction to others: The warn glow of success. Journal of Personality and Social Psychology, 1970, 15, 294-301. Johnson, D. W. Cooperativeness and social perspective taking. Journal of Personality and Social Psychology, 1975, 31, 241-244. Kameya, L. I. The effect of empathy level and role taking training upon prosocial behavior. University of Michigan, Unpublished doctoral dissertation, 1976.

Katz, R. L. Empathy, its nature and uses. London: Free Press of Glencoe, 1963.

Kohlberg, L. The development of children's orientations toward a moral order: I. Sequence in the development of moral thought. Vita Humana, $1963, \underline{6}, 11-33$. 
Krebs, D. Altruism - an examination of the concept and a review of the literature. Psychological Bulletin, 1970, 73, 258-302.

Krebs, D. Empathy and altruism. Journal of Personality and Social Psychology, 1975, 32, 1134-1146.

Krebs, D., \& Sturrup, B. Role-taking, ability and altruistic behavior in elementary school children. Paper presented at the meeting of the American Psychological Association, New Orleans, August, 1974.

Kuchenbecker, S., Feshbach, N. D., \& Pletcher, G. The effects of age, sex, and morality upon social comprehension and empathy. Paper presented at the meeting of the Western Psychological Association, San Francisco, April, 1974.

Kurdek, L. A., \& Rodgon, M. M. Perceptual, cognitive, and affective perspective taking in kindergarten through sixth-grade children. Developmental Psychology, 1975, 11, 643-650.

Latané, B., \& Darley, J. M. The unresponsive bystander: Why doesn't

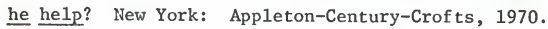

Leiman, B. Affective empathy and subsequent altruism in kindergarteners and first graders. Paper presented at the annual meeting of the American Psychological Association, Toronto, Canada, August, 1978.

Lenrow, P. B. Studies in sympathy. In S. S. Tomkins \& C. E. Izard (Eds.), Affect, cognition, and personality: Empirical studies. New York: Springer, 1965.

Levine, L. E., \& Hoffman, M. L. Empathy and cooperation in four-yearolds. Developmental Psychology, 1975, 11, 533-534. 
Lipps, T. Das Wissen von fremden Ichen. Psychol Untersuch, 1906, 1, 694-722.

Macaulay, J., \& Berkowitz, L. (Eds.), Altruism and helping behavior. New York: Academic Press, 1970.

Maccoby, E. A., \& Jacklin, C. N. The psychology of sex differences. Stanford, Calif.: Stanford University Press, 1974.

Mehrabian, A., \& Epstein, N. A measure of emotional empathy. Journa1 of Personality, 1972, 40, 525-543.

Miller, S. M. Dependency, empathy, and altruism. Paper presented at the meeting of the Society for Research in Child Development, New Orleans, March, 1977.

Moore, B. S., Underwood, B., \& Rosenhan, D. L. Affect and altruism. Developmenta1 Psychology, 1973, 8, 99-104.

Murphy, L. B. Social behavior and personality. New York: Columbia University Press, 1937.

Piaget, J. The psychology of intelligence. New York: Harcourt, Brace, and World, 1950.

Regan, D. T., \& Totten, J. Empathy and attribution: Turning observers into actors. Journal of Personality and Social Psychology, $1975,32,850-856$.

Rosenhan, D. L., Underwood, B., \& Moore, B. Affect moderates selfgratification and altruism. Journal of Personality and Socia1 Psychology, 1974, 30, 546-552.

Rubin, K. H., \& Schneider, F. W. The relationship between moral judgment, egocentrism, and altruistic behavior. Child Development, $1973,44,661-665$. 
Ruderman, D. L. An exploration of empathic ability in children and its relationship to several variables. Columbia University. Unpublished doctoral dissertation, 1961.

Rushton, J. P. Socialization and altruistic behavior in children. Psychological Bulletin, 1976, 83, 898-913.

Rushton, J. P., \& Wiener, J. Altruism and cognitive development in children. British Journal of Social and Clinical Psychology, $1975,14,341-349$.

Sagi, A., \& Hoffman, M. L. Empathic distress in newborns. Developmental Psychology, 1976, 12, 175-176.

Sawin, D. Assessing empathy in children: A search for an elusive construct. Paper presented at the bienniel meeting of the Society for Research in Child Development, San Francisco, March 1979.

Scheler, M. The nature of sympathy. Hamden, Connecticut: Archon Books, 1970.

Simner, M. L. Newborn's response to the cry of another infant. Developmental Psychology, 1971, 5, 136-150.

Spence, J. T., \& Helmreich, R. L. Children's Personality Attributes Questionnaire (CPAQ). Unpublished test. University of Texas, Austin, 1977.

Staub, E. Helping a distressed person: Social, personality, and stimulus determinants. In L. Berkowitz (Ed.), Advances in experimental social psychology. New York: Academic Press, 1974. Stewart, D. A. Preface to empathy. New York: Philosophical Library, 1956. 
Stotland, E. Exploratory investigations on empathy. In L. Berkowitz (Ed.), Advances in experimental social psychology. New York: Academic Press, 1969.

Sullivan, H. S. The interpersonal theory of psychiatry. New York: Norton, 1953.

Waxler, C. Z., Yarrow, M. R., \& Smith, J. B. Perspective taking and prosocial behavior. Developmental Psychology, 1977, 13, 87-88.

Weiss, R. F., Boyer, J. L., Lombardo, J. P., \& Stich, M. H. Altruistic drive and altruistic reinforcement. Journal of Personality and Social Psychology, 1973, 25, 390-400.

Wilson, K. V. A distribution-free test of analysis of variance hypotheses. Psychological Bulletin, 1956, 53, 96-101.

Winer, B. J. Statistical principles in experimental design. New York: McGraw-Hil1, 1971.

Yarrow, M. R., Scott, P. M., \& Waxler, C. Z. Learning concern for others. Developmental Psychology, 1973, ㅇ, 240-260. 


\section{Departmeni of Psychology}

IEANSAS Anderson Hall

STATTE Manhatten, Kansas 66506

UNTVERSTTY 913-532-6850

Appendix 1. Parenta] Permission Form

October, 1977

Dear Marlatt Schocl Parent:

During the next several weeks, the Unified School District No. 383 will be cooperating with the faculty in the Psychology Department at Kansas State University in investigating aspects of children's social development. Now we are asking for your help. Children participating in the study will be asked to view a series of slides showing children their own age engaging in a variety of activities and will be asked to answer some simple questions about the slides. The children will be awarjed a small prize at the conclusion of the study.

Each first grade child will be asked to help in this project by giving us abcut 20-25 minutes of his or her time during the next several weeks. The study involves no stress on the child. Indeed, the great majority of children find participation in these studies quite enjoyable. The names of the children will not be used in reporting the results of the study.

Please indicate on the forn below whether you will or will not allow your child to take part in this study and return the permission slip to the classruom. If you have any questions about the nature of this study, please feel iree to telephone Dr. Mark Barnett at 5326850 (Psychology Department, Kansas State University).

Thank you for your cooperation.

\section{(permission slip)}

$\square$ I will allow my child,

$\square$ I will not allow my child,

to participate in the study outlined above. 
Appendix 2. Feshbach Empathy Scale:

Scripts for Slides

H-I (Boy)

1. This boy decided to enter a contest that he learns about on T.V. The prize is two tickets for everything in Disneyland, even including food.

2. Here he is mailing his entry hoping that he will win.

3. He has won. Here he is receiving the good news in the mail and the tickets as well. Wait until his friends and family hear about his.

H-I (Gir1)

1. This gir1 decides to enter a contest that she hears about on T.V. The prize is two tickets for everything at Disneyland, even including food.

2. Here she is mailing her entry hoping that she will win.

3. She has won. Here she is receiving the good news in the mail and the tickets as we11. Wait till her friends and family hear about this.

H-II (Boy)

1. This boy has just awakened and he remembers that today is his birthday .

2. Here he is greeting his friends who are coming to his party.

3. Now he is ready to blow out the candles on his delicious cake before he opens his many presents.

H-II (Gir1)

1. This girl has just awakened and she remembers that today is her birthday.

2. Here she is greeting her friends who are coming to her party.

3. Now she is ready to blow out the candles on her delicious cake before she opens her many presents.

\section{A-I (Boy)}

1. Two boys are playing bal1. One boy is asking the other boy not to play so close to the window because it might break.

2. The boy didn't listen. The ball did hit the window and the glass shattered all over.

3. And when the owner rushed out to see what happened, the boy who really broke the window blamed it on the other boy.

\section{A-I (Gir1)}

1. Two girls are playing ball. One girl is asking the other girl not to play so close to the window because it might break.

2. The girl didn't listen. The ball did hit the window and the glass shat tered all over.

3. And when the owner rushed out to see what happened, the gir1 who really broke the window blamed it on the other girl. 


\section{A-II (Boy)}

1. The boy in the grey sweatshirt is getting ready to test his new rocket. The boy standing up is watching him.

2. The boy who was watching is trying to grab this other boy's rocket away.

3. The boy has managed to grab and take away this boy's new rocket.

\section{A-II (Girl)}

1. The girl sitting down is playing with her new Mary Poppins doll. The girl standing up is watching her.

2. The girl who was watching is trying to grab this other girl's doll away.

3. The girl did grab and take away this girl's new doll.

\section{S-I (Boy)}

1. Here is a boy and his dog. This boy goes everywhere with his dog but sometimes the dog tries to run away.

2. Here he is running away again.

3. This time the dog cannot be found and the boy realizes that the dog may be gone and lost forever.

\section{S-I (Gir1)}

1. Here is a girl and her dog. This girl goes everywhere with her dog but sonetimes the dog tries to run away.

2. Here he is running away again.

3. This time the dog cannot be found and the girl realizes that the dog may be gone and lost forever.

\section{S-II (Boy)}

1. This boy has just moved into the neighborhood. He sees some boys playing a fun game. He would love to be able to join them.

2. He asks to join in. They say "no". They have enough children and besides they really don't know him.

3. The other children continue to play. He has no one to play with.

\section{S-II (Gir1)}

1. This girl just moved into the neighborhood. She sees some girls playing a fun game. She would love to be able to join them.

2. She asks to join in. They say "no". They have enough children and besides they really don't know her.

3. The other children continue to play. She has no one to play with.

\section{F-I (Boy)}

1. This boy is picnicing with his family in a wooded forest. His parents asked him to bring some water from the well near the road.

2. He seems to have taken the wrong turn because there is no road, only trees and more forest.

3. He is getting deeper and deeper in the forest. It is getting darker. Night is coming and he cannot even see where to go. He doesn't know how to find his way back. 


\section{F-I (Gir1)}

1. This girl is picnicing with her family in a wooded forest. Her parents asked her to bring some water from the well near the road.

2. She seems to have taken the wrong turn because there is no road, only trees and more forest.

3. She is getting deeper and deeper in the forest. It is getting darker. Night is coming and she cannot even see where to go. She doesn't know how to find her way back.

\section{F-II (Boy)}

1. This boy sees a big dog. He does not know whether the dog is friendly or mean.

2. The dog begins to run after the boy. The boy tries to get away.

3. The boy is not able to get away and the mean dog is going to attack him.

\section{F-II (Gir1)}

1. This girl sees a big dog. She does not know whether the dog is friendly or mean.

2. The dog begins to run after the girl. The girl tries to get away.

3. The girl is not able to get away and the mean dog is going to attack her. 
Appendix 3. Children's Personality Attributes Questionnaire

Now I am going to tell you about some children. I want to know how much you are like each of these children. There are no right or wrong answers because all people are different.

* Put your finger at the beginning of the first row. Think about a child who watches TV a lot. This child watches as much TV as they can. I want to know how much you watch TV. Look up here while I show you how to mark. If you watch TV a lot, you will put an $\mathrm{X}$ on the big box like this. (Demonstrate on the board; then erase the X.) If you watch TV somewhat, you will put an $\mathrm{X}$ on the middle box, like this. (Demonstrate on the board, then erase the X.) If you watch TV only a little bit, you will put an X on the little box, like this. (Demonstrate on the board, then erase the $\mathrm{x}$. ) Does everybody understand? Now mark how much you watch TV. Mark how much you watch TV. (Check to see that each child has marked a box. Explain to individuals who do not understand.)

Let me tell you one more thing. Suppose you have marked a box and then want to change your answer. Suppose you have marked the middle box, like this (mark middle box) and want to change your answer to the big box. You can change your answer by scratching out the old answer, like this (demonstrate), and then marking your new answer (demonstrate).

*2. Now put your finger by row 2. Think about a child who eats a lot of vegetables. This child eats a lot of things like spinach and peas and carrots. Mark the box that shows how much you eat vegetables. Mark how much you eat vegetables. (Pause to allow all children to mark.) If you eat vegetables a lot, you should have 
marked the big box; if you eat vegetables somewhat, you should have marked the middle box; if you eat vegetables only a little, you should have marked the little box. (Check to see that each child has marked a box. Explain to individuals who do not understand.)

3. Put your finger by row 3 . Think about a child who always wants to do better than other children. This child hates to lose a game or have other kids do better than they do. This child always wants to come in first, like winning a game. Mark the box that shows how much you want to be the best. Mark how much you want to be the best.

F+ *4. Put your finger by row 4. Think about a child who is gentle. When this child plays with other kids they are very careful not to hurt them. Mark how gentle you are. Mark how gentle you are.

MF *5. Put your finger by row 5. Think about a child who cries a lot. Mark how much you cry. Mark how much you cry.

M- 6. Put your finger by row 6 at the top of the page like this. (Demonstrate and check to see that each child is in the right place.) Think about a child who gives up easily. When this child doesn't do well on something like playing a game, they give up right away. Mark how much you give up right away. Mark how much you give up right away.

F+ *7. Put your finger by row 7. Think about a child who cares about how other people are feeling. When other children are sad, this child tries to make them feel better. Mark how much you care about how other people are feeling. Mark how much you care about how other people are feeling. 
MF 8. Put your finger by row 8. Think about a child whose feelings get hurt easily. When someone isn't nice to them this child feels really bad. Mark how much your feelings get hurt easily, Mark how much your feelings get hurt easily.

14+ *9. Put your finger by row 9. Think about a child who always tries to do things for themselves. This child doesn't like to ask grownups or other kids for help if they don't have to. This child likes to do things for themselves. Mark how much you try to do things for yourself. Mark how much you always try to do things for yourself.

$\mathrm{F}+* 10$. Put your finger by row 10 . Think about a child who always lets other people know how they feel. This child always lets other people know when they are happy or sad. Mark how much you let other people know how you feel. Mark how much you let other people know how you feel.

IF 11. Now turn the page. You should see a 3 at the top of the page and some boxes on the page. (Demonstrate and check to see that each child is on page 3.) Put your finger by the first row, Think about a child who cares a lot about whether other people like them. This child wants to do things that will make other people like them. Mark how much you care a lot about what other people think of you. Mark how much you care a lot about what other people think of you.

14+ 12. Put your finger by row 2. Think about a child who can make up their mind about things. This child is always sure about what to do. Mark how sure you are about things. Mark how sure you are. 
F+ 13. Put your finger by row 3. Think about a child who is never selfish. This child always likes to do things for other people and never just for themselves. Mark how much you try to do things for other people... how much you try to do things for other people.

MF 14. Put your finger by row 4. Think about a child who always tries to get their own way. When this child wants something they try to make other people do what they want. Mark how much you try to get your own way... how much you always try to get your own way.

$M+* 15$. Put your finger by row 5 . Think about a child who is very good at things. This child does things better than other children. Mark how much you are better than other children... how much you are better than other children.

F+*16. Put your finger by row 6 at the top of the page. (Check to see that each child is in the right place.) Think about a child who is always kind. This child always likes to be nice to other people and never likes to do things that make people unhappy. Mark you kind you are... how kind you are.

MF 17. Put your finger by row 7. Think about a child who needs to have grown-ups or other kids to help them. Mark how much you need to have people help you... how much you need to have other people help you.

M+ 18. Put your finger by row 8 . Think about a child who thinks they are pretty good at whatever they try to do. Most of the time this child is sure that they can do what they try to do. Mark how much you think you are pretty good at whatever you try to do... how much you think you are pretty good at whatever you try to do. 
F+*19. Put your finger by row 9. Think about a child who is always helpful to others. This child always likes to help their friends and family. Mark how helpful you are...how helpful you are.

MF 20. Put your finger by row 10. Think about a child who is always the leader. This child's friends let them decide what they are going to do or be the boss. Mark how much you are the leader... how much you are the leader.

From: Spence \& Helmreich, 1977

Note: Asterisks denote those items used for the younger age level. The task was reduced to ten items for the younger children because the full 20 iten scale was inappropriate, time-consuming and caused the younger children to lose interest. The older children were quite able to complete the entire 20 items in approximately the same amount of time as was required for the younger children to complete the 10 items indicated. 
NAME

GRADE

BOY $\square$

GIRL

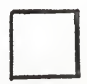


CPAP-1

$1 . \square$
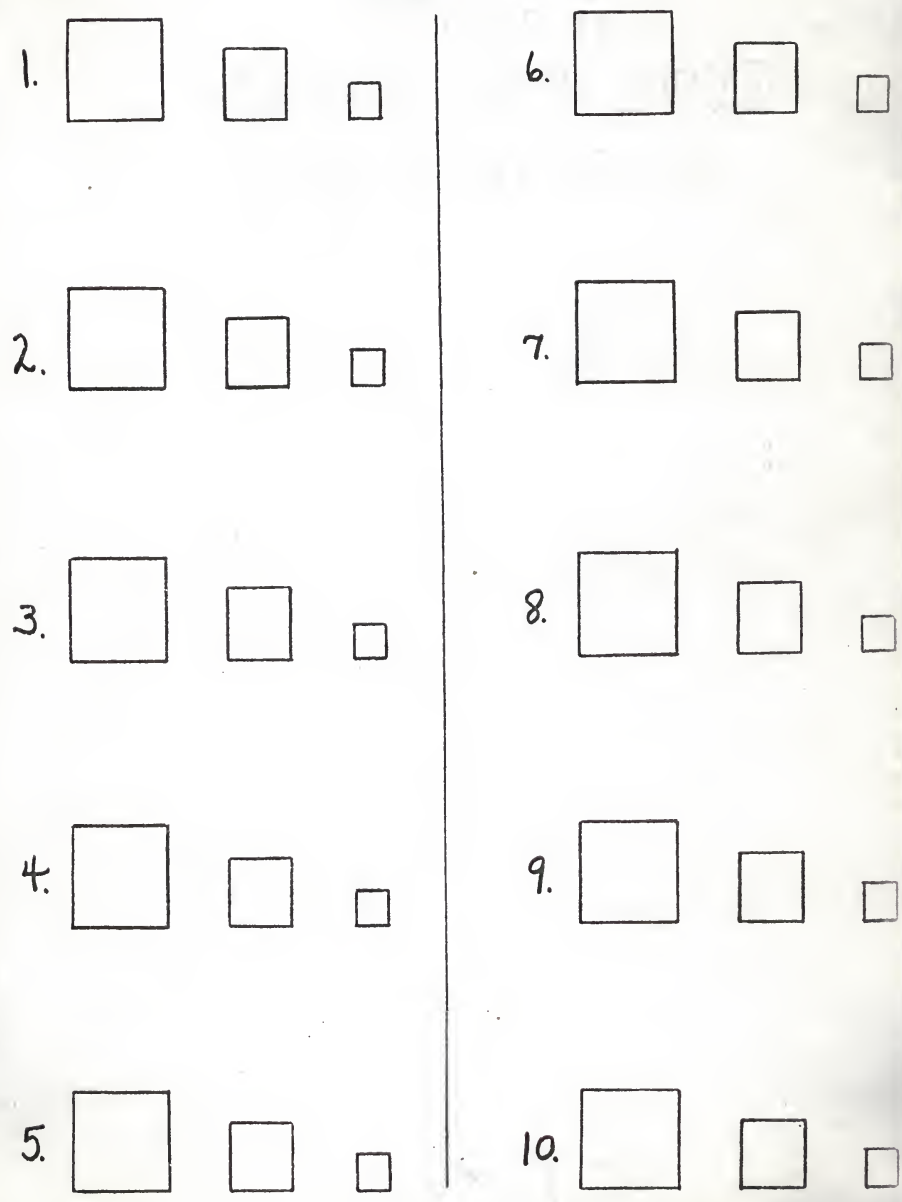
CPAO-2

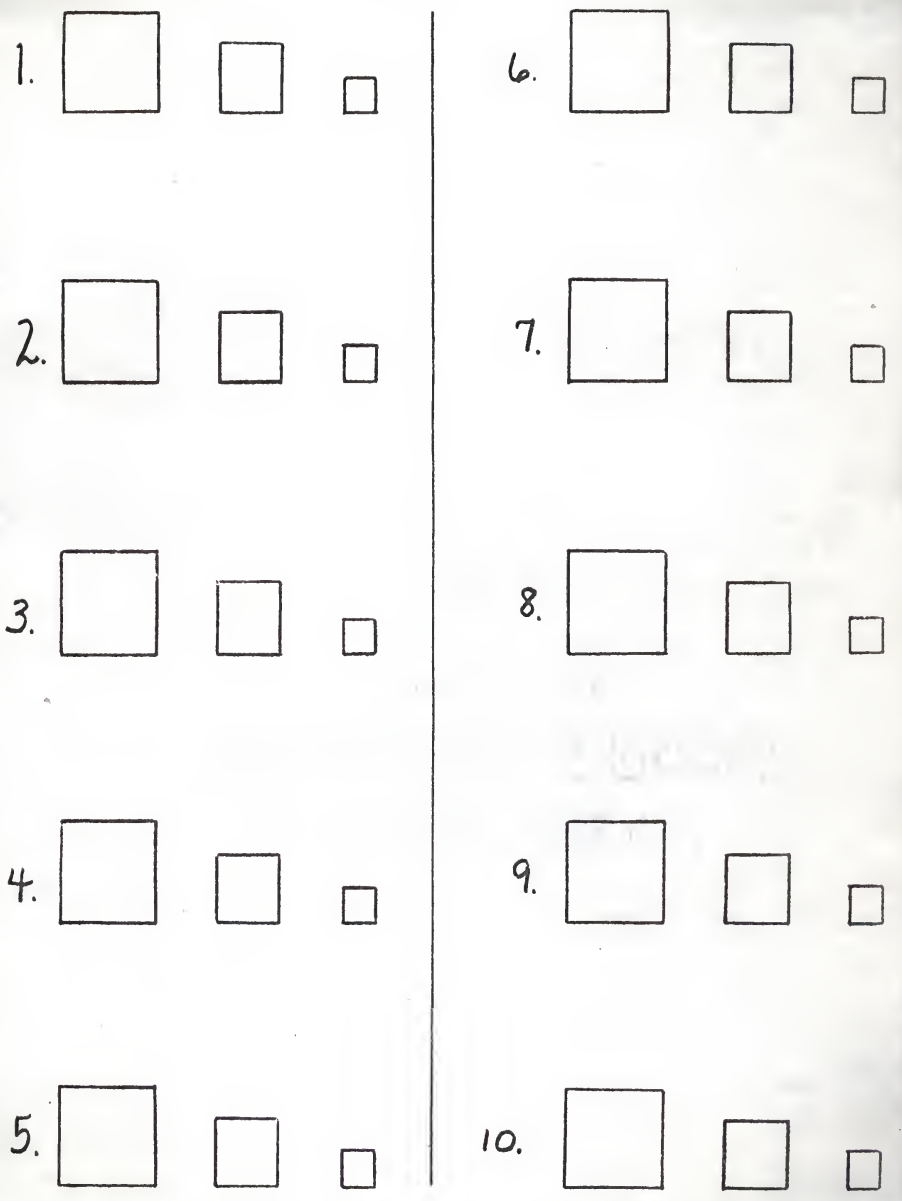


Appendix 4. Post-experimental questionnaire

(1) Remember when I gave you those prize chips? What did I say you were to do with them?
a) Did I say you had to keep them?
b) Did I say you had to give some away?
c) Did I say you could give some away if you wanted to?
d) Do you forget what I said about the prize chips?

Now I have another way I want you to answer the questions.

See these faces? This one is very sad; he/she feels very bad. This one is very happy; he/she feels very happy. This one feels a little bit sad; and this one feels a little bit happy. This one is right in the middle because he/she doesn't feel happy and he/she doesn't feel sad either. When I ask you a question, I want you to point to one of the faces which feels the way you feel.

Example 1:

How would you feel if it was your birthday and you were having a big party?

Example 2:

How would you feel if you fell down and hurt your knee?

(2) Remember when I told you about the other children who will not get any prizes? How did you feel when I told you about the other children?

(3) Remember when I told you about the other children who will not get any prizes? How did you think they would feel? 
Appendix 5. Questionnaire Response Scale

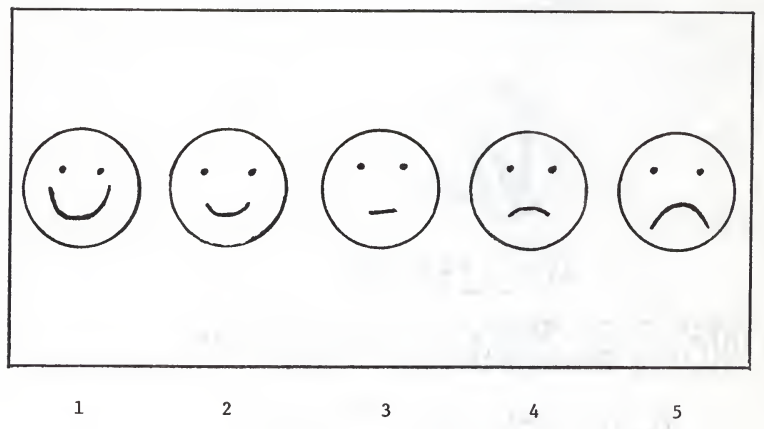

Note: The figure above is drawn $\frac{1}{2}$ scale. No numerals were included on the original response scale. The numbers given above indicate how each child's responses were scored. 


\section{Appendix 6: Raw Data}

The following information is provided for each subject:

Subject Number (No)

Sex of Subject $($ Sex $)$ Male $=1 ;$ Female $=2$

Age in Months (Age)

Age Group $(\mathrm{AG})$ older $=1$; Younger $=2$

Condition (Cond) HEA $=1 ;$ LEA $=2$

Specific affect empathy scores

a) Sad (S)

b) Angry (A)

c) Fearful (F)

d) Happy (H)

Total Empathy (TE)

Number of Tokens Donated (Donat)

Responses to Questionnaire Items
a) Question 2 (Q2)
b) Question 3 (Q3)

No Sex Age AG Cond $\mathrm{S}$ A $\mathrm{F}$ H $\mathrm{TE}$ Donat Q2 Q3

$\begin{array}{lllllllllllll}1 & 1 & 85 & 1 & 2 & 3 & 3 & 2 & 4 & 12 & 2 & 5 & 5\end{array}$

$\begin{array}{lllllllllllll}2 & 1 & 78 & 1 & 2 & 2 & 2 & 2 & 2 & 8 & 12 & 4 & 5\end{array}$

$\begin{array}{lllllllllllll}3 & 1 & 81 & 1 & 1 & 2 & 2 & 2 & 3 & 9 & 6 & 3 & 5\end{array}$

$\begin{array}{llllllllllllll}4 & 2 & 78 & 1 & 2 & 2 & 0 & 0 & 4 & 6 & 0 & 5 & 5\end{array}$

$\begin{array}{llllllllllllll}5 & 2 & 86 & 1 & 2 & 4 & 4 & 4 & 2 & 14 & 0 & 4 & 5\end{array}$

$\begin{array}{lllllllllllll}6 & 1 & 77 & 1 & 2 & 4 & 4 & 3 & 3 & 14 & 0 & 5 & 5\end{array}$

$\begin{array}{llllllllllllll}7 & 1 & 79 & 1 & 2 & 1 & 0 & 0 & 1 & 2 & 6 & 4 & 5\end{array}$

$\begin{array}{lllllllllllll}8 & 2 & 79 & 1 & 2 & 4 & 2 & 3 & 2 & 11 & 0 & 2 & 5\end{array}$

$\begin{array}{llllllllllllll}9 & 1 & 86 & 1 & 1 & 2 & 0 & 2 & 0 & 4 & 4 & 4 & 5\end{array}$




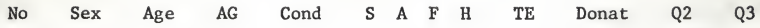
$\begin{array}{lllllllllllll}10 & 2 & 78 & 1 & 1 & 4 & 4 & 2 & 4 & 14 & 3 & 5 & 5\end{array}$ $\begin{array}{lllllllllllll}11 & 1 & 80 & 1 & 1 & 2 & 2 & 2 & 1 & 7 & 7 & 5 & 5\end{array}$ $\begin{array}{lllllllllllll}12 & 2 & 75 & 1 & 1 & 4 & 2 & 2 & 4 & 12 & 0 & 1 & 5\end{array}$ $\begin{array}{lllllllllllll}13 & 1 & 81 & 1 & 2 & 2 & 2 & 2 & 2 & 8 & 5 & 4 & 4\end{array}$ $\begin{array}{lllllllllllll}14 & 1 & 80 & 1 & 1 & 4 & 1 & 3 & 4 & 12 & 9 & 5 & 4\end{array}$ $\begin{array}{lllllllllllll}15 & 1 & 85 & 1 & 1 & 3 & 4 & 3 & 4 & 14 & 6 & 5 & 4\end{array}$ $\begin{array}{lllllllllllll}16 & 1 & 84 & 1 & 2 & 4 & 2 & 2 & 4 & 12 & 0 & 3 & 5\end{array}$ $\begin{array}{lllllllllllll}17 & 2 & 76 & 1 & 2 & 0 & 0 & 0 & 2 & 2 & 2 & 3 & 4\end{array}$ $\begin{array}{lllllllllllll}18 & 1 & 76 & 1 & 2 & 4 & 4 & 3 & 4 & 15 & 2 & 4 & 5\end{array}$ $\begin{array}{lllllllllllll}19 & 2 & 77 & 1 & 2 & 4 & 4 & 2 & 4 & 14 & 6 & 3 & 4\end{array}$ $\begin{array}{lllllllllllll}20 & 1 & 80 & 1 & 2 & 1 & 0 & 1 & 2 & 4 & 0 & 4 & 5\end{array}$ $\begin{array}{lllllllllllll}21 & 2 & 76 & 1 & 1 & 2 & 1 & 0 & 4 & 7 & 4 & 4 & 4\end{array}$ $\begin{array}{lllllllllllll}22 & 1 & 82 & 1 & 1 & 4 & 4 & 4 & 4 & 16 & 7 & 4 & 5\end{array}$ $\begin{array}{lllllllllllll}23 & 2 & 86 & 1 & 1 & 2 & 0 & 1 & 2 & 5 & 2 & 5 & 5\end{array}$ $\begin{array}{lllllllllllll}24 & 2 & 85 & 1 & 1 & 4 & 3 & 3 & 3 & 13 & 8 & 3 & 5\end{array}$ $\begin{array}{lllllllllllll}25 & 1 & 79 & 1 & 1 & 4 & 0 & 0 & 0 & 4 & 12 & 5 & 5\end{array}$ $\begin{array}{lllllllllllll}26 & 2 & 77 & 1 & 1 & 4 & 2 & 2 & 4 & 12 & 0 & 3 & 5\end{array}$ $\begin{array}{lllllllllllll}27 & 2 & 81 & 1 & 2 & 4 & 2 & 3 & 4 & 13 & 2 & 5 & 5\end{array}$ $\begin{array}{lllllllllllll}28 & 2 & 76 & 1 & 1 & 4 & 2 & 2 & 4 & 12 & 0 & 5 & 5\end{array}$ $\begin{array}{lllllllllllll}29 & 2 & 71 & 1 & 2 & 2 & 2 & 2 & 0 & 6 & 5 & 2 & 5\end{array}$ $\begin{array}{lllllllllllll}30 & 1 & 75 & 1 & 1 & 3 & 4 & 2 & 4 & 13 & 3 & 4 & 5\end{array}$ $\begin{array}{lllllllllllll}31 & 1 & 79 & 1 & 2 & 4 & 3 & 2 & 4 & 13 & 0 & 3 & 5\end{array}$ $\begin{array}{lllllllllllll}32 & 2 & 84 & 1 & 1 & 0 & 0 & 0 & 1 & 1 & 18 & 5 & 4\end{array}$ $\begin{array}{lllllllllllll}33 & 2 & 77 & 1 & 1 & 3 & 2 & 2 & 2 & 9 & 2 & 5 & 5\end{array}$ $\begin{array}{lllllllllllll}34 & 1 & 87 & 1 & 1 & 2 & 1 & 2 & 3 & 8 & 7 & 2 & 5\end{array}$ $\begin{array}{lllllllllllll}35 & 1 & 76 & 1 & 1 & 4 & 4 & 2 & 4 & 14 & 10 & 4 & 5\end{array}$ $\begin{array}{lllllllllllll}36 & 1 & 83 & 1 & 2 & 4 & 2 & 2 & 0 & 8 & 6 & 3 & 5\end{array}$ 
$\begin{array}{llllllllllll}\text { No Sex } & \text { Age AG } & \text { Cond } & \mathrm{S} & \mathrm{A} & \mathrm{F} & \mathrm{H} & \mathrm{TE} & \text { Donat } & \text { Q2 } & \text { Q3 }\end{array}$ $\begin{array}{lllllllllllll}37 & 2 & 86 & 1 & 1 & 4 & 3 & 2 & 4 & 13 & 15 & 3 & 4\end{array}$ $\begin{array}{lllllllllllll}38 & 1 & 81 & 1 & 1 & 0 & 0 & 0 & 0 & 0 & 0 & 4 & 5\end{array}$ $\begin{array}{lllllllllllll}39 & 1 & 77 & 1 & 2 & 3 & 1 & 1 & 2 & 7 & 0 & 4 & 5\end{array}$ $\begin{array}{lllllllllllll}40 & 2 & 86 & 1 & 2 & 3 & 2 & 2 & 4 & 11 & 0 & 5 & 5\end{array}$ $\begin{array}{lllllllllllll}41 & 2 & 84 & 1 & 1 & 4 & 2 & 3 & 4 & 13 & 0 & 4 & 5\end{array}$ $\begin{array}{lllllllllllll}42 & 1 & 83 & 1 & 2 & 3 & 3 & 2 & 3 & 11 & 4 & 3 & 5\end{array}$ $\begin{array}{lllllllllllll}43 & 1 & 85 & 1 & 1 & 4 & 3 & 3 & 4 & 14 & 10 & 4 & 5\end{array}$ $\begin{array}{lllllllllllll}44 & 2 & 80 & 1 & 2 & 4 & 2 & 2 & 4 & 12 & 0 & 4 & 5\end{array}$ $\begin{array}{lllllllllllll}45 & 1 & 84 & 1 & 2 & 4 & 3 & 3 & 1 & 11 & 5 & 4 & 5\end{array}$ $\begin{array}{lllllllllllll}46 & 1 & 78 & 1 & 1 & 4 & 3 & 3 & 4 & 14 & 8 & 4 & 5\end{array}$ $\begin{array}{lllllllllllll}47 & 2 & 85 & 1 & 1 & 4 & 3 & 3 & 4 & 14 & 26 & 3 & 5\end{array}$ $\begin{array}{lllllllllllll}48 & 1 & 87 & 1 & 2 & 3 & 3 & 2 & 3 & 11 & 10 & 3 & 5\end{array}$ $\begin{array}{lllllllllllll}49 & 2 & 83 & 1 & 1 & 0 & 0 & 0 & 0 & 0 & 0 & 5 & 5\end{array}$ $\begin{array}{lllllllllllll}50 & 2 & 94 & 1 & 2 & 2 & 2 & 2 & 3 & 9 & 0 & 2 & 4\end{array}$ $\begin{array}{lllllllllllll}51 & 1 & 86 & 1 & 1 & 1 & 0 & 2 & 0 & 3 & 5 & 4 & 5\end{array}$ $\begin{array}{lllllllllllll}52 & 1 & 88 & 1 & 1 & 2 & 3 & 3 & 4 & 12 & 3 & 4 & 3\end{array}$ $\begin{array}{lllllllllllll}53 & 1 & 82 & 1 & 2 & 3 & 3 & 3 & 4 & 13 & 11 & 5 & 5\end{array}$ $\begin{array}{lllllllllllll}54 & 1 & 79 & 1 & 2 & 2 & 2 & 2 & 3 & 9 & 1 & 3 & 5\end{array}$ $\begin{array}{lllllllllllll}55 & 1 & 76 & 1 & 1 & 3 & 4 & 2 & 3 & 12 & 6 & 4 & 5\end{array}$ $\begin{array}{lllllllllllll}56 & 1 & 78 & 1 & 2 & 3 & 3 & 3 & 3 & 12 & 2 & 5 & 5\end{array}$ $\begin{array}{lllllllllllll}57 & 2 & 78 & 1 & 1 & 0 & 0 & 0 & 2 & 2 & 0 & 3 & 5\end{array}$ $\begin{array}{llllllllllllll}58 & 2 & 88 & 1 & 1 & 4 & 3 & 2 & 4 & 13 & 0 & 5 & 5\end{array}$ $\begin{array}{lllllllllllll}59 & 1 & 74 & 2 & 1 & 0 & 0 & 0 & 0 & 0 & 0 & 5 & 5\end{array}$ $\begin{array}{lllllllllllll}60 & 2 & 76 & 2 & 2 & 0 & 0 & 0 & 0 & 0 & 0 & 3 & 5\end{array}$ $\begin{array}{lllllllllllll}61 & 2 & 69 & 2 & 1 & 0 & 0 & 0 & 0 & 0 & 4 & 4 & 5\end{array}$ $\begin{array}{lllllllllllll}62 & 1 & 74 & 2 & 2 & 0 & 0 & 0 & 0 & 0 & 15 & 4 & 3\end{array}$ 
$\begin{array}{lllllllllllll}\text { No Sex } & \text { Age } & \text { AG } & \text { Cond } & \text { S } & \text { A } & \text { F } & \text { H } & \text { TE } & \text { Donat } & \text { Q3 }\end{array}$ $\begin{array}{lllllllllllll}63 & 2 & 66 & 2 & 1 & 2 & 2 & 2 & 4 & 10 & 0 & 5 & 5\end{array}$ $\begin{array}{lllllllllllll}64 & 1 & 111 & 1 & 2 & 1 & 2 & 1 & 2 & 6 & 9 & 4 & 5\end{array}$ $\begin{array}{lllllllllllll}65 & 2 & 100 & 1 & 2 & 4 & 2 & 2 & 4 & 12 & 0 & 4 & 5\end{array}$ $\begin{array}{lllllllllllll}66 & 2 & 89 & 1 & 2 & 2 & 0 & 2 & 0 & 4 & 15 & 5 & 5\end{array}$ $\begin{array}{lllllllllllll}67 & 1 & 93 & 1 & 1 & 2 & 0 & 0 & 0 & 2 & 0 & 3 & 5\end{array}$ $\begin{array}{lllllllllllll}68 & 1 & 96 & 1 & 2 & 4 & 1 & 3 & 4 & 12 & 10 & 4 & 3\end{array}$ $\begin{array}{lllllllllllll}69 & 2 & 95 & 1 & 1 & 3 & 2 & 2 & 4 & 11 & 6 & 5 & 5\end{array}$ $\begin{array}{lllllllllllll}70 & 1 & 99 & 1 & 2 & 4 & 1 & 2 & 2 & 9 & 0 & 4 & 3\end{array}$ $\begin{array}{lllllllllllll}71 & 1 & 76 & 2 & 1 & 4 & 4 & 3 & 4 & 15 & 0 & 3 & 5\end{array}$ $\begin{array}{lllllllllllll}72 & 2 & 74 & 2 & 2 & 4 & 2 & 2 & 4 & 12 & 0 & 1 & 5\end{array}$ $\begin{array}{lllllllllllll}73 & 2 & 68 & 2 & 2 & 0 & 0 & 0 & 0 & 0 & 0 & 1 & 5\end{array}$ $\begin{array}{llllllllllllll}74 & 2 & 68 & 2 & 1 & 0 & 0 & 0 & 0 & 0 & 2 & 3 & 5\end{array}$ $\begin{array}{lllllllllllll}75 & 2 & 77 & 2 & 1 & 2 & 2 & 0 & 0 & 4 & 12 & 1 & 5\end{array}$ $\begin{array}{lllllllllllll}76 & 1 & 102 & 1 & 1 & 4 & 2 & 2 & 4 & 12 & 2 & 3 & 5\end{array}$ $\begin{array}{lllllllllllll}77 & 1 & 90 & 1 & 1 & 0 & 0 & 0 & 3 & 3 & 9 & 4 & 5\end{array}$ $\begin{array}{lllllllllllll}78 & 2 & 91 & 1 & 2 & 4 & 4 & 2 & 4 & 14 & 0 & 4 & 5\end{array}$ $\begin{array}{lllllllllllll}79 & 2 & 74 & 2 & 2 & 0 & 0 & 0 & 0 & 0 & 0 & 5 & 5\end{array}$ $\begin{array}{lllllllllllll}80 & 2 & 75 & 2 & 1 & 2 & 0 & 4 & 3 & 9 & 0 & 1 & 5\end{array}$ $\begin{array}{lllllllllllll}81 & 2 & 102 & 1 & 1 & 2 & 2 & 0 & 3 & 7 & 0 & 5 & 1\end{array}$ $\begin{array}{lllllllllllll}82 & 2 & 95 & 1 & 1 & 4 & 2 & 4 & 4 & 14 & 2 & 5 & 5\end{array}$ $\begin{array}{lllllllllllll}83 & 1 & 93 & 1 & 2 & 2 & 1 & 1 & 4 & 8 & 12 & 5 & 5\end{array}$ $\begin{array}{lllllllllllll}84 & 1 & 89 & 1 & 2 & 3 & 3 & 3 & 4 & 13 & 21 & 4 & 5\end{array}$ $\begin{array}{llllllllllllll}85 & 1 & 77 & 2 & 2 & 2 & 4 & 2 & 4 & 12 & 0 & 3 & 5\end{array}$ $\begin{array}{lllllllllllll}86 & 2 & 75 & 2 & 1 & 0 & 0 & 0 & 0 & 0 & 0 & 2 & 4\end{array}$ $\begin{array}{lllllllllllll}87 & 1 & 72 & 2 & 2 & 4 & 1 & 1 & 4 & 10 & 0 & 2 & 5\end{array}$ $\begin{array}{lllllllllllll}88 & 2 & 71 & 2 & 2 & 0 & 0 & 0 & 0 & 0 & 0 & 4 & 3\end{array}$ $\begin{array}{lllllllllllll}89 & 1 & 69 & 2 & 1 & 0 & 0 & 0 & 0 & 0 & 3 & 4 & 3\end{array}$ 


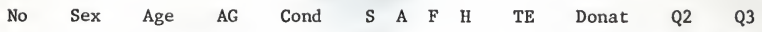
$\begin{array}{llllllllllllll}90 & 1 & 94 & 1 & 1 & 2 & 0 & 1 & 0 & 3 & 0 & 5 & 5\end{array}$ $\begin{array}{llllllllllllll}91 & 2 & 90 & 1 & 2 & 4 & 2 & 4 & 4 & 14 & 6 & 5 & 5\end{array}$ $\begin{array}{lllllllllllll}92 & 1 & 91 & 1 & 2 & 2 & 2 & 2 & 2 & 8 & 0 & 4 & 4\end{array}$ $\begin{array}{llllllllllllll}93 & 1 & 100 & 1 & 1 & 0 & 0 & 0 & 2 & 2 & 14 & 5 & 5\end{array}$ $\begin{array}{llllllllllllll}94 & 1 & 92 & 1 & 1 & 4 & 2 & 3 & 4 & 13 & 6 & 4 & 5\end{array}$ $\begin{array}{llllllllllllll}95 & 1 & 103 & 1 & 2 & 3 & 2 & 4 & 4 & 13 & 0 & 4 & 5\end{array}$ $\begin{array}{llllllllllllll}96 & 2 & 90 & 1 & 1 & 1 & 3 & 3 & 4 & 1,1 & 0 & 4 & 5\end{array}$ $\begin{array}{lllllllllllll}97 & 1 & 97 & 1 & 2 & 3 & 1 & 1 & 4 & 9 & 0 & 5 & 2\end{array}$ $\begin{array}{llllllllllllll}98 & 1 & 90 & 1 & 1 & 4 & 2 & 2 & 4 & 12 & 15 & 4 & 5\end{array}$ $\begin{array}{llllllllllllll}99 & 2 & 92 & 1 & 2 & 1 & 1 & 0 & 2 & 4 & 0 & 3 & 5\end{array}$ $\begin{array}{lllllllllllll}100 & 2 & 57 & 2 & 2 & 0 & 0 & 0 & 0 & 0 & 9 & 3 & 5\end{array}$ $\begin{array}{lllllllllllll}101 & 1 & 57 & 2 & 1 & 0 & 4 & 0 & 4 & 8 & 10 & 3 & 4\end{array}$ $\begin{array}{lllllllllllll}102 & 1 & 63 & 2 & 1 & 0 & 0 & 0 & 0 & 0 & 12 & 4 & 5\end{array}$ $\begin{array}{lllllllllllll}103 & 1 & 60 & 2 & 2 & 0 & 0 & 0 & 0 & 0 & 2 & 2 & 5\end{array}$ $\begin{array}{lllllllllllll}104 & 1 & 57 & 2 & 1 & 4 & 4 & 3 & 4 & 15 & 0 & 4 & 5\end{array}$ $\begin{array}{lllllllllllll}105 & 1 & 48 & 2 & 2 & 0 & 0 & 0 & 0 & 0 & 0 & 1 & 5\end{array}$ $\begin{array}{lllllllllllll}106 & 2 & 56 & 2 & 1 & 4 & 3 & 2 & 3 & 12 & 0 & 2 & 5\end{array}$ $\begin{array}{lllllllllllll}107 & 1 & 65 & 2 & 2 & 4 & 4 & 1 & 4 & 13 & 3 & 1 & 5\end{array}$ $\begin{array}{lllllllllllll}108 & 2 & 48 & 2 & 1 & 0 & 0 & 0 & 0 & 0 & 0 & 2 & 5\end{array}$ $\begin{array}{lllllllllllll}109 & 1 & 70 & 2 & 1 & 2 & 2 & 2 & 4 & 10 & 0 & 5 & 5\end{array}$ $\begin{array}{lllllllllllll}110 & 1 & 68 & 2 & 1 & 2 & 2 & 3 & 4 & 11 & 0 & 5 & 5\end{array}$ $\begin{array}{llllllllllllll}111 & 1 & 66 & 2 & 2 & 0 & 0 & 4 & 0 & 4 & 1 & 3 & 5\end{array}$ $\begin{array}{lllllllllllll}112 & 1 & 77 & 2 & 1 & 3 & 3 & 4 & 1 & 11 & 0 & 5 & 5\end{array}$ $\begin{array}{lllllllllllll}113 & 1 & 70 & 2 & 2 & 2 & 2 & 0 & 2 & 6 & 0 & 1 & 4\end{array}$ $\begin{array}{llllllllllllll}114 & 1 & 74 & 2 & 1 & 4 & 4 & 3 & 4 & 15 & 4 & 3 & 5\end{array}$ $\begin{array}{llllllllllllll}115 & 1 & 76 & 2 & 1 & 4 & 2 & 2 & 4 & 12 & 15 & 5 & 5\end{array}$ $\begin{array}{lllllllllllll}116 & 1 & 71 & 2 & 1 & 0 & 0 & 0 & 4 & 4 & 0 & 5 & 5\end{array}$ 
$\begin{array}{lllllllllllll}\text { No } & \text { Sex } & \text { Age } & \mathrm{Ag} & \text { Cond } & \mathrm{S} & \mathrm{A} & \mathrm{F} & \mathrm{H} & \mathrm{TE} & \text { Donat } & \text { Q2 } & \text { Q3 }\end{array}$ $\begin{array}{lllllllllllll}117 & 1 & 75 & 2 & 2 & 4 & 2 & 4 & 2 & 12 & 0 & 3 & 3\end{array}$ $\begin{array}{lllllllllllll}118 & 2 & 73 & 2 & 1 & 4 & 0 & 3 & 2 & 9 & 6 & 5 & 5\end{array}$ $\begin{array}{lllllllllllll}119 & 2 & 76 & 2 & 1 & 4 & 2 & 3 & 4 & 13 & 0 & 4 & 5\end{array}$ $\begin{array}{lllllllllllll}120 & 2 & 75 & 2 & 2 & 4 & 1 & 4 & 4 & 13 & 0 & 5 & 5\end{array}$ $\begin{array}{lllllllllllll}121 & 1 & 75 & 2 & 2 & 4 & 1 & 2 & 4 & 11 & 2 & 4 & 5\end{array}$ $\begin{array}{llllllllllllll}122 & 2 & 75 & 2 & 1 & 4 & 4 & 4 & 4 & 16 & 7 & 5 & 5\end{array}$ $\begin{array}{lllllllllllll}123 & 2 & 74 & 2 & 2 & 4 & 0 & 4 & 2 & 10 & 4 & 4 & 5\end{array}$ $\begin{array}{lllllllllllll}124 & 2 & 72 & 2 & 2 & 0 & 0 & 0 & 4 & 4 & 0 & 5 & 5\end{array}$ $\begin{array}{llllllllllllll}125 & 2 & 70 & 2 & 2 & 4 & 4 & 1 & 4 & 13 & 2 & 5 & 5\end{array}$ $\begin{array}{llllllllllllll}126 & 2 & 69 & 2 & 2 & 4 & 2 & 1 & 4 & 11 & 0 & 3 & 5\end{array}$ $\begin{array}{lllllllllllll}127 & 1 & 74 & 2 & 2 & 2 & 4 & 1 & 2 & 9 & 3 & 4 & 5\end{array}$ $\begin{array}{lllllllllllll}128 & 2 & 76 & 2 & 1 & 4 & 3 & 2 & 4 & 13 & 0 & 3 & 5\end{array}$ $\begin{array}{lllllllllllll}129 & 2 & 75 & 2 & 2 & 4 & 3 & 2 & 4 & 13 & 0 & 3 & 4\end{array}$ $\begin{array}{llllllllllllll}130 & 2 & 74 & 2 & 1 & 4 & 4 & 4 & 4 & 16 & 8 & 5 & 5\end{array}$ $\begin{array}{lllllllllllll}131 & 2 & 77 & 2 & 1 & 4 & 3 & 3 & 4 & 14 & 2 & 5 & 5\end{array}$ $\begin{array}{llllllllllllll}132 & 1 & 69 & 2 & 2 & 3 & 4 & 1 & 4 & 12 & 0 & 4 & 5\end{array}$ $\begin{array}{lllllllllllll}133 & 2 & 71 & 2 & 2 & 4 & 3 & 2 & 4 & 13 & 6 & 5 & 5\end{array}$ $\begin{array}{lllllllllllll}134 & 2 & 67 & 2 & 2 & 0 & 0 & 0 & 0 & 0 & 1 & 5 & 4\end{array}$ $\begin{array}{llllllllllllll}135 & 2 & 70 & 2 & 1 & 4 & 3 & 1 & 4 & 12 & 0 & 4 & 5\end{array}$ $\begin{array}{lllllllllllll}136 & 2 & 78 & 2 & 2 & 4 & 2 & 2 & 2 & 10 & 0 & 1 & 5\end{array}$ $\begin{array}{llllllllllllll}137 & 2 & 72 & 2 & 1 & 0 & 0 & 1 & 4 & 5 & 0 & 4 & 5\end{array}$ $\begin{array}{lllllllllllll}138 & 2 & 73 & 2 & 1 & 1 & 0 & 1 & 0 & 2 & 0 & 4 & 4\end{array}$ $\begin{array}{lllllllllllll}139 & 2 & 72 & 2 & 2 & 2 & 2 & 2 & 4 & 10 & 0 & 5 & 5\end{array}$ $\begin{array}{llllllllllllll}140 & 1 & 53 & 2 & 1 & 2 & 3 & 2 & 4 & 11 & 0 & 1 & 5\end{array}$ $\begin{array}{lllllllllllll}141 & 2 & 61 & 2 & 2 & 3 & 3 & 0 & 4 & 10 & 2 & 1 & 5\end{array}$ $\begin{array}{llllllllllllll}142 & 1 & 53 & 2 & 2 & 4 & 4 & 2 & 4 & 14 & 0 & 1 & 5\end{array}$ 


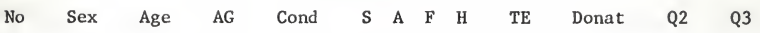
$\begin{array}{llllllllllllll}143 & 1 & 57 & 2 & 1 & 4 & 0 & 2 & 4 & 10 & 8 & 5 & 5\end{array}$ $\begin{array}{lllllllllllll}144 & 1 & 53 & 2 & 2 & 2 & 2 & 2 & 2 & 8 & 0 & 1 & 5\end{array}$ $\begin{array}{lllllllllllll}145 & 2 & 65 & 2 & 1 & 4 & 3 & 3 & 4 & 14 & 4 & 5 & 5\end{array}$ $\begin{array}{lllllllllllll}146 & 2 & 57 & 2 & 1 & 3 & 1 & 0 & 3 & 7 & 20 & 4 & 5\end{array}$ $\begin{array}{lllllllllllll}147 & 2 & 64 & 2 & 1 & 1 & 1 & 0 & 1 & 3 & 0 & 4 & 4\end{array}$ $\begin{array}{lllllllllllll}148 & 1 & 46 & 2 & 2 & 0 & 0 & 0 & 0 & 0 & 15 & 1 & 1\end{array}$ $\begin{array}{lllllllllllll}149 & 2 & 57 & 2 & 2 & 0 & 0 & 0 & 0 & 0 & 1 & 1 & 5\end{array}$ $\begin{array}{lllllllllllll}150 & 1 & 56 & 2 & 1 & 0 & 0 & 1 & 0 & 1 & 8 & 5 & 5\end{array}$ $\begin{array}{lllllllllllll}151 & 2 & 57 & 2 & 1 & 1 & 1 & 2 & 2 & 6 & 5 & 5 & 5\end{array}$ $\begin{array}{lllllllllllll}152 & 2 & 46 & 2 & 2 & 2 & 0 & 1 & 4 & 7 & 0 & 1 & 4\end{array}$ $\begin{array}{lllllllllllll}153 & 2 & 50 & 2 & 2 & 0 & 0 & 0 & 0 & 0 & 30 & 3 & 5\end{array}$ $\begin{array}{lllllllllllll}154 & 1 & 51 & 2 & 2 & 2 & 2 & 0 & 4 & 8 & 20 & 1 & 5\end{array}$ $\begin{array}{lllllllllllll}155 & 1 & 52 & 2 & 2 & 0 & 0 & 0 & 0 & 0 & 0 & 1 & 2\end{array}$ $\begin{array}{lllllllllllll}156 & 1 & 52 & 2 & 1 & 0 & 0 & 1 & 0 & 1 & 0 & 1 & 5\end{array}$ $\begin{array}{llllllllllllll}157 & 2 & 62 & 2 & 1 & 4 & 2 & 1 & 4 & 11 & 0 & & 5 & 5\end{array}$ $\begin{array}{lllllllllllll}158 & 1 & 59 & 2 & 1 & 3 & 3 & 3 & 4 & 13 & 9 & 3 & 5\end{array}$ $\begin{array}{lllllllllllll}159 & 1 & 52 & 2 & 2 & 0 & 0 & 2 & 2 & 4 & 0 & 3 & 5\end{array}$ $\begin{array}{lllllllllllll}160 & 2 & 45 & 2 & 2 & 0 & 0 & 1 & 2 & 3 & 15 & 1 & 5\end{array}$ $\begin{array}{lllllllllllll}161 & 2 & 48 & 2 & 1 & 0 & 0 & 0 & 0 & 0 & 8 & 1 & 5\end{array}$ $\begin{array}{lllllllllllll}162 & 1 & 59 & 2 & 1 & 0 & 0 & 0 & 2 & 2 & 18 & 1 & 5\end{array}$ $\begin{array}{lllllllllllll}163 & 2 & 62 & 2 & 1 & 3 & 0 & 0 & 0 & 3 & 2 & 4 & 5\end{array}$ $\begin{array}{lllllllllllll}164 & 1 & 48 & 2 & 2 & 1 & 0 & 0 & 0 & 1 & 1 & 4 & 5\end{array}$ $\begin{array}{lllllllllllll}165 & 1 & 48 & 2 & 1 & 0 & 0 & 0 & 0 & 0 & 1 & 5 & 1\end{array}$ $\begin{array}{lllllllllllll}166 & 2 & 49 & 2 & 2 & 0 & 0 & 0 & 4 & 4 & 0 & 1 & 5\end{array}$ $\begin{array}{lllllllllllll}167 & 2 & 53 & 2 & 2 & 0 & 0 & 0 & 0 & 0 & 0 & 2 & 3\end{array}$ $\begin{array}{lllllllllllll}168 & 1 & 59 & 2 & 2 & 4 & 1 & 0 & 0 & 5 & 0 & 2 & 1\end{array}$ 


$\begin{array}{rrrrrrrrrrrrr}\text { No } & \text { Sex } & \text { Age } & \text { AG } & \text { Cond } & \text { S } & \text { A } & \text { F } & \text { H } & \text { TE } & \text { Donat } & \text { Q2 } & \text { Q3 } \\ 169 & 1 & 46 & 2 & 1 & 0 & 0 & 0 & 0 & 0 & 0 & 2 & 3 \\ 170 & 2 & 47 & 2 & 1 & 0 & 0 & 0 & 0 & 0 & 0 & 3 & 5\end{array}$


AROUSAL OF EMPATHY AND SUBSEQUENT

GENEROSITY IN YOUNG CHILDREN

by

JEFFREY A. HOWARD

B.A., Valparaiso University, 1976

AN ABSTRACT OF A MASTER'S THESIS

submitted in partial fulfillment of the

requirements for the degree

MASTER OF SCIENCE

Department of Psychology

KANSAS STATE UNIVERSITY

Manhattan, Kansas

1979 


\section{Abstract}

Arousal of Empathy and Subsequent Generosity in Young Children

Empathizing, or experiencing the emotions of another person, has frequently been postulated as an important motivator of altruistic acts. Although this assertion has been supported with adults (e.g., Coke, Batson, \& McDavis, 1978), there have been no direct experimental manipulations of empathy in young children. The present study explored the effect of eliciting empathic arousal on subsequent sharing in young children previously assessed as either high or low on a measure of dispositional empathy.

The Feshbach and Roe (1968) empathy measure was administered individually to 85 boys and 76 girls enrolled in preschool through secondgrade classes in a town in northeastern Kansas. The sample was predominately Caucasian and from middle-class backgrounds. One month following the empathy measure, each child played a simple game and received 30 plastic tokens which were described as redeemable for prizes upon completion of the study. The children were informed that there were some boys and girls from another class who would not be able to receive any prizes, but that they might share their tokens with them if they wished. Children were randomly assigned to one of two conditions in which they were either (1) encouraged to focus on the feelings of the less fortunate others (utilizing an empathyarousal procedure previously used with adults [Stotland, 1969]), or (2) encouraged to think about the less fortunate others, but with no mention of feelings being made. Each child was then given an opportunity to donate some prize tokens, in private, to the other children. 
The children in the empathy-arousal condition (1) reported fee1ing significantly sadder and (2) donated significantly more prize tokens than children in the no empathy-arousal condition. No main or interaction effects of dispositional empathy were found. In addition, a main effect of age level was found for both donations and affect. The results suggest that focusing the young child specifically upon the feelings of needy others may enhance the expression of charitable behaviors. Moreover, the encouragement of empathy may have a favorable influence on young children at differing levels of dispositional empathy. Implications for childrearing and discipline techniques which may promote the development of prosocial behaviors were discussed. 